\title{
HR-LC-ESI-Orbitrap-MS-Based Metabolic Profiling Coupled with Chemometrics for the Discrimination of Different Echinops spinosus Organs and Evaluation of Their Antioxidant Activity
}

\author{
Amel Bouzabata ${ }^{1, *}$, Paola Montoro ${ }^{2}$ D , Katarzyna Angelika Gil ${ }^{3}{ }^{(D}$, Sonia Piacente ${ }^{2}$, Fadia S. Youssef $4{ }^{(D)}$, \\ Nawal M. Al Musayeib ${ }^{5}$, Geoffrey A. Cordell 6,7 (D), Mohamed L. Ashour ${ }^{4 * \mathbb{D}}$ and \\ Carlo Ignazio Giovanni Tuberoso ${ }^{3, * \text { D }}$
}

check for updates

Citation: Bouzabata, A.; Montoro, P.; Gil, K.A.; Piacente, S.; Youssef, F.S.; Al Musayeib, N.M.; Cordell, G.A.; Ashour, M.L.; Tuberoso, C.I.G. HR-LC-ESI-Orbitrap-MS-Based Metabolic Profiling Coupled with Chemometrics for the Discrimination of Different Echinops spinosus Organs and Evaluation of Their Antioxidant Activity. Antioxidants 2022, 11, 453. https://doi.org/10.3390/ antiox11030453

Academic Editors: Wlodzimierz Opoka and Bożena Muszyńska

Received: 29 January 2022 Accepted: 18 February 2022 Published: 24 February 2022

Publisher's Note: MDPI stays neutral with regard to jurisdictional claims in published maps and institutional affiliations.

Copyright: (C) 2022 by the authors. Licensee MDPI, Basel, Switzerland. This article is an open access article distributed under the terms and conditions of the Creative Commons Attribution (CC BY) license (https:// creativecommons.org/licenses/by/ $4.0 /)$.
1 Department of Pharmacy, Faculty of Medicine, Zaafrania Street BP 205, Annaba 23000, Algeria

2 Department of Pharmacy, University of Salerno, Via Giovanni Paolo II, 132, 84084 Fisciano, SA, Italy; pmontoro@unisa.it (P.M.); piacente@unisa.it (S.P.)

3 Department of Life and Environmental Sciences, University of Cagliari, University Campus, S.P. Monserrato-Sestu km 0.700, 09042 Monserrato, CA, Italy; kasiagil8a@gmail.com

4 Department of Pharmacognosy, Faculty of Pharmacy, Ain-Shams University, Abbasia, Cairo 11566, Egypt; fadiayoussef@pharma.asu.edu.eg

5 Department of Pharmacognosy, College of Pharmacy, King Saud University, Riyadh 11495, Saudi Arabia; nalmusayeib@ksu.edu.sa

6 Natural Products Inc., Evanston, IL 60202, USA; pharmacog@gmail.com

7 Department of Pharmaceutics, College of Pharmacy, University of Florida, Gainesville, FL 32610, USA

* Correspondence: amelbouz2009@gmail.com (A.B.); ashour@pharma.asu.edu.eg (M.L.A.); tuberoso@unica.it (C.I.G.T.)

Abstract: This study aimed to assess and correlate the phenolic content and the antioxidant activity of the methanol extracts of the stems, roots, flowers, and leaves of Echinops spinosus L. from northeastern Algeria. Qualitative analysis was performed by high-resolution mass spectrometry (HR) LC-ESI-Orbitrap-MS and (HR) LC-ESI-Orbitrap-MS/MS). Forty-five compounds were identified in the methanol extracts; some are described for the first time in E. spinosus. Targeted phenolic compounds were quantified by HPLC-DAD and it was shown that caffeoyl quinic derivatives were the most abundant compounds. Chemometric analysis was performed using principal component analysis (PCA) and hierarchical cluster analysis (HCA) based on the qualitative and quantitative LC data. The score plot discriminates different Echinopsis spinosus organs into three distinct clusters, with the stems and flowers allocated in the same cluster, reflecting their resemblance in their secondary metabolites. The antioxidant activities of the methanol extracts were assessed using cupric reducing antioxidant capacity (CUPRAC), ferric reducing antioxidant assay (FRAP), diphenyl picryl hydrazyl radical-scavenging capacity assay $\left(\mathrm{DPPH}^{\bullet}\right)$, and 2,2' -azinobis-(3-ethylbenzothiazoline-6-sulfonic acid $\left(\mathrm{ABTS}^{\bullet+}\right)$. The root extract exhibited the highest antioxidant activity, evidenced by 3.26 and $1.61 \mathrm{mmol}$ $\mathrm{Fe}^{2+} / \mathrm{g}$ dried residue for CUPRAC and FRAP, respectively, and great free radical-scavenging activities estimated by 0.53 and 0.82 mmol TEAC/g dried residue for $\mathrm{DPPH}^{\bullet}$ and $\mathrm{ABTS}^{\bullet+}$, respectively. The methanol extract of the roots demonstrated a significant level of total phenolics (TP: $125.16 \mathrm{mg}$ GAE/g dried residue) and flavonoids (TFI: 25.40 QE/g dried residue TFII: 140 CE/g dried residue). Molecular docking revealed that tricaffeoyl-altraric acid and dicaffeoyl-altraric acid exhibited the best fit within the active sites of NADPH oxidase (NO) and myeloperoxidase (MP). From ADME/TOPAKT analyses, it can be concluded that tricaffeoyl-altraric acid and dicaffeoyl-altraric acid also revealed reasonable pharmacokinetic and pharmacodynamic characteristics with a significant safety profile.

Keywords: antioxidant activity; chemometrics; Echinops; phenolics; HPLC-DAD; ADME/TOPAKT 


\section{Introduction}

Oxidative stress can be defined as a condition in which the oxidative forces override the antioxidant mechanisms within the body owing to the absence of balance among them. It is implicated in the pathogenesis of a plethora of widely spread ailments that are closely related to lifestyle, comprising hypertension, atherosclerosis, ischemic heart diseases, diabetes mellitus, and cancer [1,2]. Free radicals are considered naturally occurring reactive compounds inside the human body. They can elicit both beneficial and harmful effects, with the former observed in the immune system and the latter evident in proteins, lipids, and DNA [3]. Thus, the antioxidant system that constitutes complex protection is highly demanded by living organisms to oppose and abolish these hazardous effects. Plant-derived polyphenolic compounds have long been used as a promising source of antioxidants that can boost the antioxidant system and counteract oxidative stress [2,4].

The genus Echinops L. (Asteraceae) comprises about 130 species, many of which are used in traditional medicine, mainly in Africa and Asia [5]. E. spinosus (synonyms: E. spinosissimus Turra) is distributed in North Africa, the Mediterranean basin, and temperate regions towards Central Asia [6]. E. spinosus is widely used in traditional medicine to treat inflammation-related diseases [7]. The internal part of the inflorescence is used for kidney ailments [8], in post-partum care [9], and as a hypoglycemic plant for treating diabetes mellitus [10].

In Algeria, the roots and fruits of E. spinosus subsp. bovei are used as an abortifacient and for treating labor pains and neuralgia [11], and as a spice in Morocco and Cameroon [12,13]. Meanwhile, a decoction of the roots in either water or olive oil is given to help pregnant women in delivery via stimulation of uterine contractions. It is also used for stomach pain, indigestion, and lack of appetite; for diabetes as a diuretic or depurative; and to cure liver diseases [14]. These activities are strongly correlated with the abundance of secondary metabolites belonging to diverse classes such as alkaloids, sesquiterpenes, flavonoids, and polyphenolic compounds in different organs of E. spinosus [15].

By evaluating the current literature, it was clear that the information on the metabolites of E. spinosus is fragmentary due to the differences in both the solvents and plant parts used for extraction. Therefore, a more detailed investigation of the methanol extracts prepared from the stems, roots, flowers, and leaves of E. spinosus was performed. Qualitative analysis was performed by high-resolution mass spectrometry ((HR) LC-ESI-Orbitrap-MS and (HR) LC-ESI-Orbitrap-MS/MS) and targeted phenolic compounds were quantified using HPLC-DAD. A chemometric analysis represented by principal component analysis (PCA) and hierarchical cluster analysis (HCA) was performed, which relied upon the collected LC data, aiming to classify the measured samples into discriminant clusters according to the quantity and quality of polyphenolic compounds that in turn reflected on its biological activity. Besides, the antioxidant activities of the methanol extracts were assessed using different antioxidant tests, namely, the cupric reducing antioxidant capacity (CUPRAC), ferric reducing antioxidant assay (FRAP), diphenyl picryl hydrazyl radicalscavenging capacity assay (DPPH ${ }^{\bullet}$ ), and 2,2'-azinobis-(3-ethylbenzothiazoline-6-sulfonic acid $\left(\mathrm{ABTS}^{\bullet+}\right)$. Correlations were done based on the total phenol and the total flavonoid contents determined by spectrophotometric assays. Furthermore, molecular docking of the major polyphenolic compounds identified from different organs of the E. spinosus methanol extract was performed within the active sites of two enzymes that are responsible for the production of (ROS), which are NADPH oxidase (NO) and myeloperoxidase (MP). Meanwhile, the pharmacodynamic, pharmacokinetic, and toxicity properties of these compounds were exposed to ADMET evaluation (absorption, distribution, metabolism, excretion, and toxicity), as well as to toxicity prediction (TOPKAT) studies.

\section{Materials and Methods}

\subsection{Chemicals and Reagents}

All the solvents and chemicals used in this study were analytical grade. Methanol, ethanol, acetonitrile LC-MS grade, formic acid LC-MS grade, 85\% phosphoric acid, and wa- 
ter LC-MS grade were purchased from Merck ${ }^{\circledR}$ (Darmstadt, Germany). Gallic acid, quinic acid, caffeic acid, ferulic acid, protocatechuic acid, neochlorogenic acid (3-O-caffeoylquinic acid), chlorogenic acid (5-O-caffeoylquinic acid), cynarin (1,3-dicaffeoylquinic acid), isochlorogenic acid, kaempferol-3-O-glucoside, quercetin-3-O-glucoside, ferrous sulfate, 1,1-diphenyl2-picrylhydrazyl radical $\left(\mathrm{DPPH}^{\bullet}\right),( \pm)$-6-hydroxy-2,5,7,8-tetramethylchroman-2-carboxylic acid (Trolox), 2,4,6-tris(2-pyridyl) -1,3,5-triazine (TPTZ), 2,2'-azino-bis(3-ethylbenzothiazoline)6-sulfonic acid (ABTS), Folin-Ciocalteu reagent, sodium carbonate, ferric chloride, $\mathrm{AlCl}_{3}$, $\mathrm{NaNO}_{2}$, and $\mathrm{CuSO}_{4} \cdot 5 \mathrm{H}_{2} \mathrm{O}$ were purchased from Merck ${ }^{\circledR}$, Sigma-Aldrich ${ }^{\circledR}$, or Fluka ${ }^{\mathrm{TM}}(\mathrm{Mi}$ lan, Italy). Flavonoid standards of apigenin, apigenin-7-O-glucoside, hesperidin, hesperetin, luteolin-7-O-glucoside, naringin, and naringenin were purchased from Extrasynthese (Genay, France). Ultrapure water $(18 \mathrm{M} \Omega \cdot \mathrm{cm})$ was obtained with a Milli-Q Advantage A10 System apparatus (Millipore, Milan, Italy).

\subsection{Plant Materials}

Samples of Echinops spinosus subsp. bovei (Boiss) Murb were wild-collected in 2017 from the El Tarf district situated in northeastern Algeria. Voucher specimens were deposited in the herbarium of the Conservatory and Botanical Garden, Geneva, Switzerland, under reference number G00403753. Identification of the species was carried out by Dr. G. Debelaire by correlating the morphological characters with those described in the literature and identified as E. bovei Maire [16]. Samples of E. spinosus were divided into four parts: stems $(\mathrm{S})$, roots $(\mathrm{R})$, flowers $(\mathrm{F})$, and leaves $(\mathrm{L})$. The different plant parts were cleaned, dried in the shade, and crushed into powder, as traditionally used.

\subsection{Preparation of the Aqueous Methanol Extracts}

Extracts were prepared by the addition of $20 \mathrm{~mL}$ of $80 \%$ methanol to $2 \mathrm{~g}$ of dried powdered plant material. Extraction was performed using ultrasonification for $30 \mathrm{~min}$ at $15^{\circ} \mathrm{C}$, followed by centrifugation for $15 \mathrm{~min}$ at $10^{\circ} \mathrm{C}$ using $4000 \mathrm{rpm}$. The liquid phase was separated from the plant material and filtered using $0.45 \mu \mathrm{m}$ CA w/GMF Whatman. The extraction procedure was repeated on the marc and the liquid phases were combined (final dilution $1: 20, w / v)$ with methanol. Solutions were appropriately diluted in the range of 1:10-1:100 v/v for the cupric reducing antioxidant capacity (CUPRAC), ferric reducing antioxidant assay (FRAP), diphenyl picryl hydrazyl radical-scavenging capacity assay (DPPH·), 2,2'-azinobis(3-ethylbenzothiazoline-6-sulfonic acid $\left(\mathrm{ABTS}^{\bullet+}\right.$ ), total phenolic (TP), and total flavonoids (TF) assays. For LC-MS and LC-DAD analysis, methanol extracts were dried under $\mathrm{N}_{2}$, and a sample $(1 \mathrm{mg})$ was dissolved in $\mathrm{MeOH}: \mathrm{H}_{2} \mathrm{O}(1: 1)$ to a final concentration of $1 \mathrm{mg} / \mathrm{mL}$. The dry residue of the plant extracts was evaluated in triplicate by drying the solution $(500 \mu \mathrm{L})$ for $5 \mathrm{~h}$ in a thermostatic oven at $105 \pm 1^{\circ} \mathrm{C}$ to constant weight.

\subsection{Qualitative Investigation of E. spinosus Using LC-ESI-Orbitrap-MS and LC-ESI-Orbitrap-MS/MS and LC-DAD Analysis}

For the qualitative investigation of the methanol extracts of different E. spinosus organs, LC-ESI-(LIT) MS and LC-ESI-(LIT) MS/MS techniques were performed. Preliminarily, the electrospray ionization (ESI) source of a Thermo Scientific LTQ-Orbitrap XL (Thermo Scientific, Dreieich, Germany) mass spectrometer was tuned in the negative ion mode with a standard solution $(1 \mu \mathrm{g} / \mathrm{mL})$ of kaempferol-3-O-glucoside and injected at a flow rate of $5 \mu \mathrm{L} / \mathrm{min}$ using a syringe pump. Calibration of the Orbitrap analyzer used the standard LTQ calibration mixture composed of caffeine and the peptide MRFA (from the manufacturer Thermo Scientific, Dreieich, Germany) dissolved in 50:50 v/v\% water/acetonitrile solution. The resolution for the Orbitrap mass analyzer was set at 30,000. Spectra were acquired by full-range acquisition total ion current (TIC) covering a range of $\mathrm{m} / \mathrm{z} 180-1600$. When working in LC-MS, instrument control, data acquisition, and data processing were performed with Xcalibur 2.0 software (Thermo Fisher Scientific, Bremen, Germany). LC/ESI/ LIT Orbitrap MS experiments were achieved using a Thermo Fisher Scientific liquid chromatography system comprised of a quaternary Accela 600 pump and an Accela autosam- 
pler, connected to a linear Trap-Orbitrap hybrid mass spectrometer (LTQ-Orbitrap XL, Thermo Fisher Scientific) with electrospray ionization (ESI). LC-ESI-Orbitrap-MS analyses were performed using a Phenomenex Luna C18 $(150 \mathrm{~mm} \times 2.1 \mathrm{~mm}$, particle size $5 \mu \mathrm{m}) \mathrm{col}-$ umn, eluted with water containing $0.1 \%$ formic acid (solvent $\mathrm{A}$ ) and acetonitrile containing $0.1 \%$ formic acid (solvent B). A linear gradient program at a flow rate of $0.200 \mathrm{~mL} / \mathrm{min}$ was adopted employing the following protocol: 0-35 min, from 5 to $95 \%$ (B), and 35-40 $\mathrm{min}$, returning to $5 \%$ and back to $5 \%$ (B) for an additional $5 \mathrm{~min}$. A total of $10 \mu \mathrm{L}$ of a solution $(1 \mathrm{mg} / \mathrm{mL})$ of the extract in water was injected. The ESI source and MS parameters were as follows: capillary voltage $-12 \mathrm{~V}$; tube lens voltage -121.47 ; capillary temperature $280^{\circ} \mathrm{C}$; sheath and auxiliary gas flow $\left(\mathrm{N}_{2}\right) 15$ and 5 , respectively; sweep gas 0 ; spray voltage 5 . MS spectra were acquired by full-range acquisition covering $\mathrm{m} / \mathrm{z} 180-1400$. For fragmentation studies, a data-dependent scan experiment was performed, selecting precursor ions corresponding to the two most intensive peaks in the LC-MS analysis.

\subsection{Quantitative Determination of E. spinosus Major Phenolic Compounds Using HPLC-DAD}

Quantitative analysis on targeted phenolic compounds was carried out using a modified HPLC-DAD method, as previously described by Deiana et al. [17]. Polar compounds were identified and determined using an Agilent 1260 Infinity II HPLC system (Varian, Leinì, TO, Italy) fitted with a pump module G7111A, an autosampler module G7129A, and an Agilent G4212B photodiode array detector (Agilent Technologies, Cernusco sul Naviglio, MI, Italy). Separation was obtained with a Kinetex PFP C18 column $(150 \times 4.60 \mathrm{~mm}, 5 \mu \mathrm{m}$, Phenomenex, Casalecchio di Reno, Bologna, Italy) using 0.22 M phosphoric acid (solvent A) and acetonitrile (solvent B) as mobile phase at a constant flow rate of $1.0 \mathrm{~mL} / \mathrm{min}$. The gradient $(v / v)$ was generated by decreasing from $100 \%$ solvent A to $80 \%$ in $20 \mathrm{~min}$, to $70 \%$ in $35 \mathrm{~min}$, to $0 \%$ in $45 \mathrm{~min}$, and then remaining stable up to $50 \mathrm{~min}$; finally, the gradient reached $100 \%$ and was stabilized for 5 min before the subsequent injection. The chromatograms and spectra were elaborated with an OpenLab V. 2.51 data system (Agilent Technologies, Cernusco sul Naviglio, MI, Italy), and flavonoids were detected and measured at $360 \mathrm{~nm}$, ferulic acid derivatives at $313 \mathrm{~nm}$, and all the other metabolites at $280 \mathrm{~nm}$. Stock standard solutions were prepared in methanol, and the working standard solutions were prepared in ultrapure water. The calibration curves for commercial standards were plotted with the method of the external standard, correlating the peak area with the concentration by means of the least-squares method, with a coefficient of determination $\left(r^{2}\right)>0.998$ in the range of $0.4-40 \mathrm{mg} / \mathrm{L}$ for all the compounds. Limits of detection and quantification (LOD and LOQ, respectively) were evaluated in agreement with the International Conference on Harmonisation of Technical Requirements for Registration of Pharmaceuticals for Human Use (ICH) guidance note that describes the validation of analytical methods (ICH Topic Q2, 2006).

\subsection{Discrimination of the Different E. spinosus Organs Using Multivariate Data Analysis}

Chemometric analysis represented by principal component analysis (PCA) and hierarchical cluster analysis (HCA) was performed that relied upon the collected LC data. PCA as an unsupervised pattern recognition technique was conducted to provide a clear insight for all observations that were collected from the samples and then they were classified into discriminant classes in accordance with the quantity and quality of major phenolic compounds that undoubtedly influence the antioxidant activity. Furthermore, HCA was performed, adopting the entire linkage approach used for group classification. PCA and HCA were performed using CAMO's Unscrambler ${ }^{\circledR}$ X 10.4 software (Computer-Aided Modeling, As, Norway) as previously described $[18,19]$.

\subsection{In Vitro Evaluation of the Antioxidant Activity of Different E. spinosus Organs \\ 2.7.1. Cupric Reducing Antioxidant Capacity (CUPRAC) Assay}

The cupric ion-reducing antioxidant capacity (CUPRAC) assay is based upon the redox reaction, producing a chromogen of $\mathrm{Cu}(\mathrm{I})$-neocuproine. The reaction was monitored 
by spectrophotometric measurements where absorbance was measured at $450 \mathrm{~nm}$. A total of $1 \mathrm{~mL}$ water, $500 \mu \mathrm{L}$ copper (II) chloride, $500 \mu \mathrm{L}$ neocuproine, $500 \mu \mathrm{L}$ ammonium acetate, and $100 \mu \mathrm{L}$ methanol (blank), standard, or sample were added to $10 \mathrm{~mm}$ polystyrene cuvettes in that order. Quantitative analysis was performed using the external standard method (ferrous sulfate, $0.1-2 \mathrm{mmol}$ ), correlating the absorbance $(\lambda 450 \mathrm{~nm})$ with the concentration, and the spectrophotometric readings were carried out on a Varian Cary 50 Scan spectrophotometer (Varian, Leini, Turin, Italy). The results are expressed as millimoles of $\mathrm{Fe}^{2+}$ per $\mathrm{g}$ of dry extract [20].

\subsubsection{Ferric Reducing Antioxidant Assay (FRAP Assay)}

Ferric reducing antioxidant assay (FRAP) is based upon the reduction of ferric 2,4,6tris(2-pyridyl)-1,3,5-triazine (Fe(III)-TPTZ) to blue-colored ferrous complex by antioxidants in the presence of acidic medium. The reduction was monitored by spectrophotometric measurements of absorbance at $593 \mathrm{~nm}$ using a Varian Cary 50 spectrophotometer. Two $\mathrm{mL}$ of freshly prepared reagent that was composed of $0.3123 \mathrm{~g}$ TPTZ and $0.5406 \mathrm{~g} \mathrm{FeCl} \cdot 6 \mathrm{H}_{2} \mathrm{O}$ in $100 \mathrm{~mL}$ acetate buffer of $\mathrm{pH} 3.6$ were added to $20 \mu \mathrm{L}$ of the extract solution with a concentration of 1:200 w/v in $10 \mathrm{~mm}$ polystyrene cuvettes. Quantitative analysis was done using the external standard method, employing ferrous sulfate in the range of $0.1-2 \mathrm{mmol}$, correlating the absorbance at $\lambda=593 \mathrm{~nm}$ with the concentration. The results were expressed as millimoles of $\mathrm{Fe}^{2+}$ per $\mathrm{g}$ of dry extract [20].

\subsubsection{Diphenyl Picryl Hydrazyl Radical-Scavenging Capacity Assay (DPPH•)}

This method is based on the scavenging of DPPH radicals by antioxidants present in the sample. $\mathrm{DPPH}^{\bullet}$ radicals absorbed at $517 \mathrm{~nm}$, and the reaction was monitored by spectrophotometric measurement, where a decrease in absorbance was observed. A total of $50 \mu \mathrm{L}$ of extract or standard in the concentration of 1:200 w/v (using methanol as solvent of dilution) was added to $10 \mathrm{~mm}$ cuvettes with $2 \mathrm{~mL} \mathrm{DPPH}{ }^{\bullet}$ solution $(0.04 \mathrm{mmol} / \mathrm{L}$ in methanol) with concomitant mixing. The spectrophotometric readings were carried out on a Varian Cary 50 spectrophotometer at $517 \mathrm{~nm}$ after $60 \mathrm{~min}$. A calibration curve in the range of $0.02-1.0 \mathrm{mmol} / \mathrm{L}$ was prepared for Trolox, and the data are expressed as the Trolox equivalent antioxidant capacity (TEAC mmol/g dried residue) [20].

2.7.4. Free Radical-Scavenging Ability Determination Using a Stable 2,2'-azino-bis(3-ethylbenzothiazoline)-6-sulfonic acid Radical Cation (ABTS ${ }^{\bullet+}$ )

An ABTS radical cation $\left(\mathrm{ABTS}^{\bullet+}\right.$ ) was produced by reacting ABTS stock solution with $70 \mathrm{mM}$ potassium persulfate (final concentration), and the mixture was allowed to stand in the dark at room temperature for $12-16 \mathrm{~h}$ before use. After this time, $4 \mathrm{~mL}$ of the reaction mixture were diluted with water and $0.08 \mathrm{mM}$ ABTS solution was obtained. The preparation absorbance was checked $(0.70 \pm 0.02)$ at $734 \mathrm{~nm}$. The ABTS ${ }^{\bullet+}$ radical absorbs at $734 \mathrm{~nm}$, and the reaction was monitored by spectrophotometric measurement of the decrease in absorbance. A total of $20 \mu \mathrm{L}$ of the extract or the standard in the concentration of 1:200 w/ $v$ was added to $10 \mathrm{~mm}$ cuvettes with $2 \mathrm{~mL}$ of ABTS solution $(0.08 \mathrm{mmol} / \mathrm{L}$ in $\mathrm{H}_{2} \mathrm{O}$ ) and mixed. The spectrophotometric readings were carried out on a Varian Cary 50 spectrophotometer at $734 \mathrm{~nm}$ immediately after sample preparation. The calibration curve in the range of $0.02-1.0 \mathrm{mmol} / \mathrm{L}$ was prepared for Trolox, and the data are expressed as Trolox equivalent antioxidant capacity (TEAC mmol/g dried residue) [20].

\subsection{Determination of the Total Phenolic Content}

The total phenolic content was determined spectrophotometrically using a modified Folin-Ciocalteu method [17]. Briefly, in each volumetric flask, $500 \mu \mathrm{L}$ of Folin-Ciocalteu phenol reagent were added to $100 \mu \mathrm{L}$ of $1: 200(w / v)$ of the tested samples. After $5 \mathrm{~min}$, $3 \mathrm{~mL}$ of $10 \% \mathrm{Na}_{2} \mathrm{CO}_{3}(w / v)$ were added, and the mixture was shaken and diluted with $\mathrm{H}_{2} \mathrm{O}$ to a final volume of $10 \mathrm{~mL}$. After incubation for $90 \mathrm{~min}$ at room temperature, the absorbance was read at $725 \mathrm{~nm}$ using a $10 \mathrm{~mm}$ polystyrene cuvette with a Varian Cary 
50 spectrophotometer against a blank. The total phenolic content was expressed as $\mathrm{mg} / \mathrm{g}$ of gallic acid equivalent (GAE) using a calibration curve derived from freshly prepared gallic acid standard solutions (10-200 mg/g dried residue) [20].

\subsection{Determination of Total Flavonoid Content}

Total flavonoid (TF) content was determined according to the method previously described by Pękal and Pyrzynska [21] with some modifications [17] using two assays. In the first assay that was given the abbreviation TF1, $200 \mu \mathrm{L}$ of the diluted sample were mixed with $1.5 \mathrm{~mL}$ water and added to $500 \mu \mathrm{L}$ of $2 \%(w / v)$ aqueous $\mathrm{AlCl}_{3}$ solution. The mixture was allowed to stand at room temperature for $30 \mathrm{~min}$ and absorbance was determined at $425 \mathrm{~nm}$. Meanwhile, in the second assay that was termed TF2, $200 \mu \mathrm{L}$ of the diluted sample were mixed with $1 \mathrm{~mL}$ water and added to $100 \mu \mathrm{L}$ of $5 \%(w / v)$ aqueous $\mathrm{NaNO}_{2}$ solution. After $5 \mathrm{~min}, 500 \mu \mathrm{L}$ of $2 \%(w / v)$ of aqueous $\mathrm{AlCl}_{3}$ solution were added, then $500 \mu \mathrm{L}$ of $1 \mathrm{M} \mathrm{NaOH}$ were added after $6 \mathrm{~min}$, followed by incubation for $10 \mathrm{~min}$. Then the absorbance was determined at $510 \mathrm{~nm}$. The results for TF are expressed as $\mathrm{mg} / \mathrm{g}$ dried residue of quercetin $(\mathrm{QE})$ or catechin $\mathrm{CE}$ ) equivalent for assays 1 and 2, respectively.

\subsection{Computer-Aided Drug Design Studies}

\subsubsection{Molecular Docking}

Molecular docking was performed for the major polyphenolic compounds identified from different organs of E. spinosus methanol extract within the active sites of two enzymes that are responsible for the production of (ROS), which are NADPH oxidase (NO) (PDB ID: 2CDU; $1.80 \AA$ ) and myeloperoxidase (MP) (PDB ID: 5WDG; 2.40 Åobtained from the protein data bank (PDB). The docking study was performed using Discovery Studio 4.5 (Accelrys Inc., San Diego, CA, USA) employing the C-Docker protocol as previously described [18,22]. Meanwhile, the binding energies $(\Delta G)$ were calculated in accordance with the following equation $[22,23]$ :

$$
\Delta G_{\text {binding }}=\mathrm{E}_{\text {complex }}-\left(\mathrm{E}_{\text {protein }}+\mathrm{E}_{\text {ligand }}\right)
$$

where:

$\Delta G_{\text {binding: }}$ the ligand-protein interaction binding energy;

$\mathrm{E}_{\text {complex }}$ : the potential energy for the complex of the protein bound with the ligand;

$\mathrm{E}_{\text {protein: }}$ the potential energy of the protein alone and;

$\mathrm{E}_{\text {ligand: }}$ the potential energy for the ligand alone.

\subsubsection{ADME/TOPKAT Prediction}

To determine the pharmacodynamic, pharmacokinetic, and toxicity properties of the major polyphenolic compounds identified from different organs of E. spinosus methanol extract, they were exposed to ADMET evaluation (absorption, distribution, metabolism, excretion, and toxicity) as well as to toxicity prediction (TOPKAT) employing Discovery Studio 4.5 software (Accelrys Inc., San Diego, CA, USA). Plasma protein-binding prediction (PPB), human intestinal absorption (HIA), blood-brain barrier penetration (BBB), aqueous solubility, cytochrome P450 2D6, and hepatotoxicity level were chosen as the ADMET parameters. However, Ames mutagenicity, dermal and ocular irritation, and carcinogenic effect on male and female rat NPT (National Toxicology Program), as well as chronic LOAEL (lowest observed adverse effect level) and rat oral and inhalational LD50 and aerobic biodegradability, were selected as TOPKAT descriptors [24,25].

\subsection{Statistical Analyses}

All measurements were conducted in triplicate using one-way analysis of variance (ANOVA) followed by Tukey's test, which was performed to ascertain the possible significant differences between groups using the Graph Pad Prism 5 software (Graph Pad software, San Diego, CA, USA). Correlation analysis was performed and the evaluation of statistical significance of observed differences was performed using Pearson coefficients of correlation. 


\section{Results and Discussion}

The dry residues obtained after extraction of the dried plants showed different yields depending on the botanical part extracted. The lower extraction yields were observed from the root and stem parts estimated by $0.05 \pm 0.01$ and $0.10 \pm 0.01 \mathrm{~g} / \mathrm{g}$ dried plants, respectively, whereas the flowers and leaves showed higher yields of $0.15 \pm 0.01$ and $0.20 \pm 0.01 \mathrm{~g} / \mathrm{g}$ dried plants, respectively. These differences can be explained by the virtue of the difference in structure between different tissues, which might hinder extraction, and/or the amount of polar compounds and their solubilization rate in alcohol [26].

\subsection{LC-ESI-Orbitrap-MS and (HR) LC-ESI-Orbitrap-MS/MS and LC-DAD Analysis of E. spinosus Extracts}

The main interest in performing the metabolic profiling of E. spinosum relied on the limited information about the chemical content of the different plant parts, and this concomitantly resulted in the performance of qualitative liquid chromatography coupled with the high-resolution mass spectrometry (HPLC-MS) method, aiming to identify the polar metabolites occurring in the extracts that were prepared from the stems, flowers, leaves, and roots of E. spinosum. In a preliminary step, (HR) LC-ESI-Orbitrap-MS and (HR) LCESI-Orbitrap-MS/MS analyses of E. spinosum extracts, namely, stems, roots, flowers, and leaves, were conducted in negative and positive ion modes. The negative ionization mode was selected based on the larger number of compounds that were detected as giving good ionization. The negative LC-MS metabolic profiles highlighted the presence of 45 metabolites, most of them identified or tentatively identified by their $\mathrm{m} / \mathrm{z}$ values obtained through high-resolution mass spectrometry, extracted from the total ion current (TIC) profile, and implemented with the MS/MS fragmentation obtained in LC/ESI/(Orbitrap). MS/MS experiments were accomplished using a dependent data scan to submit the major ions in TIC profiles to fragmentation experiments using the MS parameters previously selected by ESI/MS and ESI-MS/MS direct introduction experiments. The registered fragmentation information was compared with the literature data of the selected compounds (Table 1). Experimental MS/MS spectra were compared with literature fragmentation patterns or those reported in a public repository of mass spectral data, such as Mass Bank [27], and associated with a comparison with a database like KNapSacK (www.knapsackfamily.com accessed on 12 July 2021). This information was coupled with a study of the genus Echinopsis and the chemotaxonomy of the Asteraceae family, which allowed the identification of most of the compounds, with the exception of compounds reported as unknown, as illustrated in Table 1, following a metabolomics approach, as reported in the literature for different species $[17,28]$. The use of pure commercial standards enabled the distinction of compounds with identical $\mathrm{m} / \mathrm{z}$ values and MS/MS fragmentation patterns. The identification of compounds based on high-resolution mass spectrometry data, chemical formulas derived from accurate mass measurements, retention times, MS/MS results, and literature references are illustrated in Table 1. High-resolution mass values did not differ by more than $5 \mathrm{ppm}$ with respect to the exact mass calculated for the same molecule (Figure 1).

The negative ion LC-MS metabolite profiles highlighted the presence of 45 peaks corresponding to 45 compounds, 10 of which are unidentified. Interestingly, only five of the identified compounds were previously reported from E. spinosus, namely, campesterol (22), stigmasterol (24), apigenin-7- $\beta$-O-(4"-O-trans- $p$-coumaroyl-glucoside (25), cholesterol (29), and brassicasterol (30) [15,29-31]. Eleven compounds were previously reported in other Echinops species and were identified here for the first time in E. spinosus as quinic acid (2), neochlorogenic acid (3-O-caffeoylquinic acid) (6), chlorogenic acid (5-Ocaffeoylquinic acid) (7), 3,5-dicaffeoylquinic acid (cynarin) (9), apigenin-6-O-arabinoside-8$\mathrm{O}$-galactoside (13), 3,4-dicaffeoylquinic acid (14), apigenin-6-O-arabinoside-8-O-glucoside (15), 3,5-dicaffeoylquinic acid (16), 4,5-dicaffeoylquinic acid (17), luteolin-7-O-glucoside (18), and rutin (21) [32-36]. However, seven compounds were previously reported in plants of the Asteraceae family, but not from the Echinops species, and have been identified as protocatechuic acid hexoside (4), dicaffeoyl altraric acid (8), dicaffeoyl altraric acid isomer (12), 
tricaffeoylaltraricric acid (19), shimobashiraside C (23), trihydroxy-octadecadienoic $(9,12,13$ trihydroxy-10,15-octadecadienoic acid, $(9,12,13$, TriHODE $(10,15))$ acid $(\mathbf{2 8})$, and trihydroxyoctadecenoic acid (9,12,13-trihydroxy-10-octadecenoic acid, 9,12,13-TriHOME(10), pinellic acid) (33) [32,37-40]. However, five compounds were identified for the first time in the genus Echinops and in the family Asteraceae. Compound (5) showed a molecular ion at $m / z[\mathrm{M}-\mathrm{H}]^{-} 359.07479$, corresponding to a molecular formula of $\mathrm{C}_{18} \mathrm{H}_{15} \mathrm{O}_{8}$. The fragmentation spectrum showed a main fragment ion at $m / z 197.05[\mathrm{M}-\mathrm{H}-162]^{-}$(corresponding to the loss of one unit of a hexose); a similar fragmentation was previously reported by Abdel et al. [41] and the compound was thus identified as a syringic acid glycoside. Compound (11) showed a molecular ion at $m / z[\mathrm{M}-\mathrm{H}]^{-} 677.1714$, corresponding to molecular formula $\mathrm{C}_{31} \mathrm{H}_{33} \mathrm{O}_{17}$. The MS/MS spectrum showed two main fragment ions at $m / z 515.14[\mathrm{M}-\mathrm{H}-162]^{-}$(corresponding to the loss of one hexose unit) and at $\mathrm{m} / \mathrm{z}$ 353.09; through database searching, the metabolite was identified as dicaffeoylquinic acid glycoside. Compound (20) showed a molecular ion at $m / z[\mathrm{M}-\mathrm{H}]^{-} 499.1237$, corresponding to the molecular formula $\mathrm{C}_{25} \mathrm{H}_{23} \mathrm{O}_{11}$. In this instance, three main fragment ions were observed at $m / z 353.09,337.09$, and 191.06, and the compound was identified as a coumaroyl-caffeoylquinic acid. Compound (36) showed a molecular ion at $m / z[\mathrm{M}-\mathrm{H}]^{-}$ 579.1497, corresponding to $\mathrm{C}_{30} \mathrm{H}_{27} \mathrm{O}_{12}$. The fragmentation spectrum showed two main fragment ions at $\mathrm{m} / \mathrm{z} 271.06$ and 307.08 , and the metabolite was identified as a naringenincoumaroyl-glucopyranoside, previously reported in the genus Crataegus [42]. Compound (40) showed a molecular ion at $m / z[\mathrm{M}-\mathrm{H}]^{-} 619.1443$, corresponding to $\mathrm{C}_{32} \mathrm{H}_{27} \mathrm{O}_{13}$. In this case, the fragmentation spectrum showed a main fragment ion at $m / z 269$, and the compound was proposed to be a derivative of apigenin.

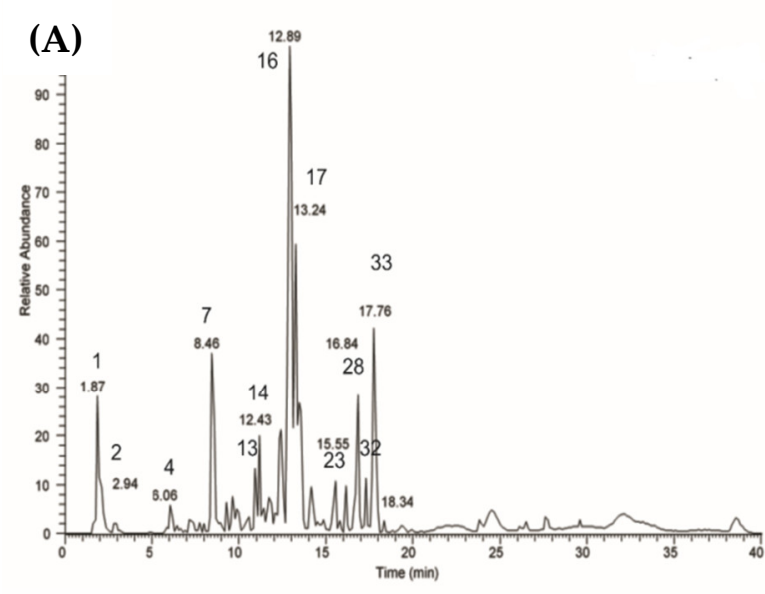

(C)

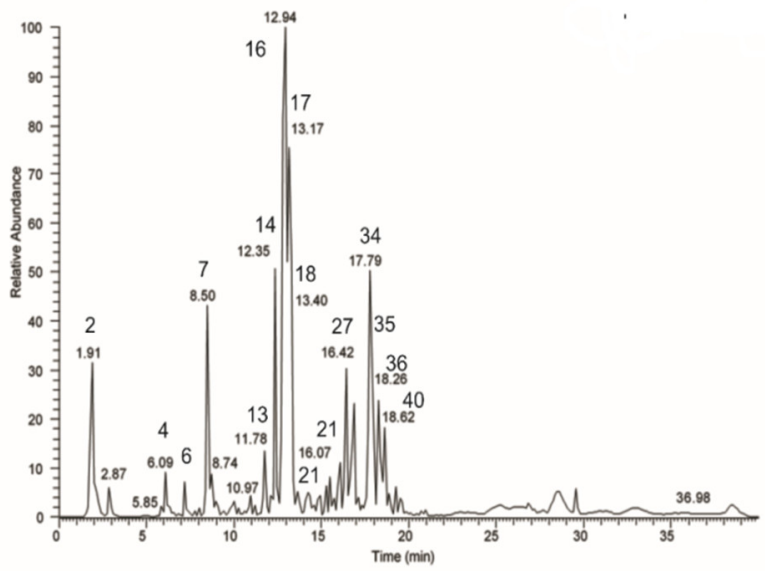

(B)

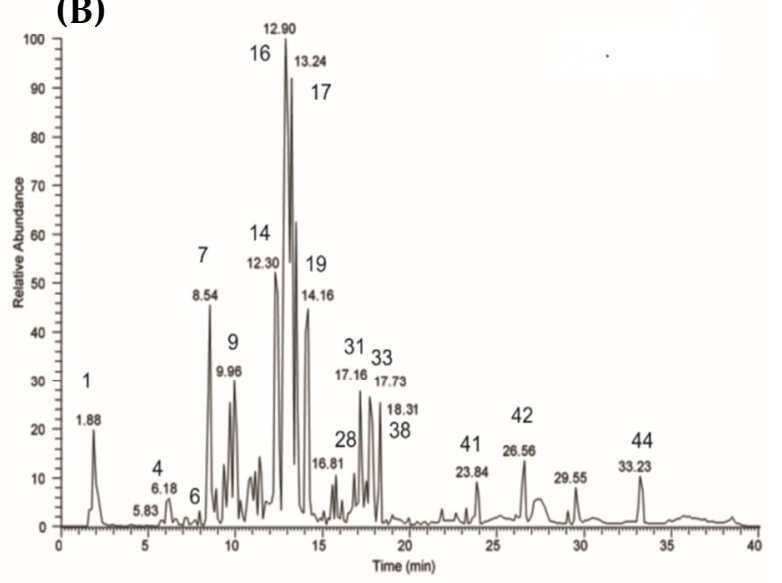

(D)

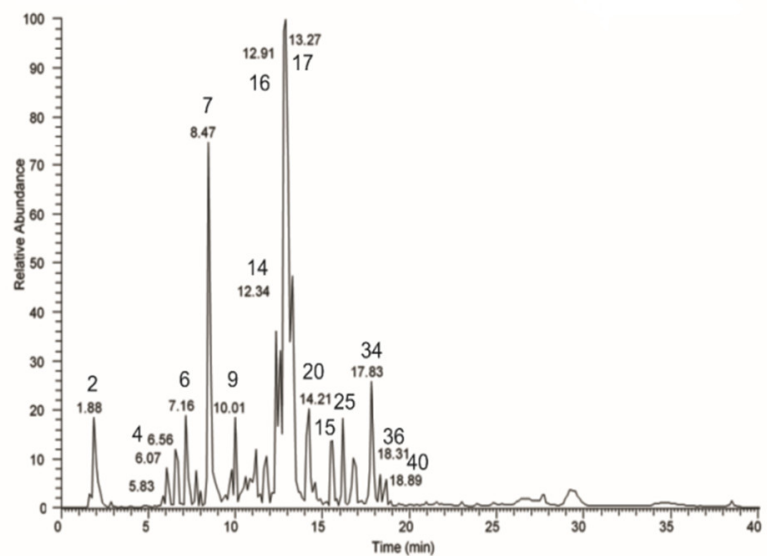

Figure 1. LC-ESI-Orbitrap-MS of extract obtained from the stems (A), roots (B), flowers (C), and leaves (D) of Echinopsis spinosus L. 
Table 1. Qualitative identification of major compounds in E. spinosus extracts (S, stems; R, roots; F, flowers; L, leaves; X, present; -, absent) by LC-ESI-Orbitrap-MS and LC-ESI-Orbitrap-MS/MS analysis.

\begin{tabular}{|c|c|c|c|c|c|c|c|c|c|c|c|}
\hline $\begin{array}{l}\text { Peak } \\
\text { No. }\end{array}$ & $\mathbf{R}_{\mathrm{t}}$ & {$[\mathbf{M}-\mathbf{H}]^{-}$} & $\begin{array}{l}\text { Molecular } \\
\text { Formula }\end{array}$ & $\Delta \mathrm{Ppm}$ & MS/MS & Identity & $\mathbf{S}$ & $\mathbf{R}$ & F & $\mathbf{L}$ & References \\
\hline 1 & 1.87 & 377.0855 & $\mathrm{C}_{18} \mathrm{H}_{17} \mathrm{O}_{9}$ & -3.258 & 341.11 & Caffeic acid derivative & $X$ & $x$ & - & - & [27] \\
\hline 2 & 1.91 & 191.0563 & $\mathrm{C}_{7} \mathrm{H}_{11} \mathrm{O}_{6}$ & 6.833 & $\begin{array}{c}85.03 / \\
93.04 / \\
127.04 / \\
173.05\end{array}$ & Quinic acid & $x$ & - & - & $x$ & {$[34,43]$} \\
\hline 3 & 5.83 & 329.0871 & $\mathrm{C}_{14} \mathrm{H}_{17} \mathrm{O}_{9}$ & 1.281 & 167.04 & Unknown & - & - & - & $x$ & - \\
\hline 4 & 6.06 & 315.0715 & $\mathrm{C}_{13} \mathrm{H}_{15} \mathrm{O}_{9}$ & 1.592 & 153.02 & Protocatechuic acid hexoside & $x$ & $x$ & $x$ & $x$ & [32] \\
\hline 5 & 6.33 & 359.0747 & $\mathrm{C}_{18} \mathrm{H}_{15} \mathrm{O}_{8}$ & -3.77 & 197.05 & Syringic acid glycoside & - & - & $x$ & - & [44] \\
\hline 6 & 7.24 & 353.0872 & $\mathrm{C}_{16} \mathrm{H}_{17} \mathrm{O}_{9}$ & 1.449 & $\begin{array}{l}179.03 / \\
191.06\end{array}$ & Neochlorogenic acid (3-CQA) & - & $x$ & $x$ & $x$ & [34] \\
\hline 7 & 8.46 & 353.0872 & $\mathrm{C}_{16} \mathrm{H}_{17} \mathrm{O}_{9}$ & 1.449 & $\begin{array}{l}179.03 / \\
191.06\end{array}$ & Chlorogenic acid (5-CQA) & $x$ & $x$ & $x$ & $x$ & [34] \\
\hline 8 & 9.65 & 533.0929 & $\mathrm{C}_{24} \mathrm{H}_{21} \mathrm{O}_{14}$ & 0.597 & $\begin{array}{l}371.06 / \\
209.03\end{array}$ & Dicaffeoyl altraric acid & $x$ & $x$ & - & - & [39] \\
\hline 9 & 9.96 & 515.1187 & $\mathrm{C}_{25} \mathrm{H}_{23} \mathrm{O}_{12}$ & 0.713 & 353.09 & 3,5-Dicaffeoylquinic acid & - & $x$ & - & $x$ & [36] \\
\hline 10 & 10.93 & 565.1919 & $\mathrm{C}_{27} \mathrm{H}_{33} \mathrm{O}_{13}$ & 0.695 & $\begin{array}{l}327.12 / \\
339.12\end{array}$ & Unknown & $x$ & - & - & - & \\
\hline 11 & 11.16 & 677.1714 & $\mathrm{C}_{31} \mathrm{H}_{33} \mathrm{O}_{17}$ & 0.242 & $\begin{array}{l}515.14 / \\
353.09 \\
\end{array}$ & $\begin{array}{l}\text { Dicaffeoylquinic acid } \\
\text { glycoside }\end{array}$ & $x$ & - & & - & [27] \\
\hline 12 & 11.42 & 533.09271 & $\mathrm{C}_{24} \mathrm{H}_{21} \mathrm{O}_{14}$ & 0.241 & 371.06 & Dicaffeoyl altraric isomer acid & - & $x$ & - & - & [39] \\
\hline 13 & 11.78 & 563.1417 & $\mathrm{C}_{26} \mathrm{H}_{27} \mathrm{O}_{14}$ & 3.860 & - & $\begin{array}{c}\text { Apigenin-6-O-arabinoside-8- } \\
\text { O-galactoside }\end{array}$ & - & - & $x$ & - & [33] \\
\hline 14 & 12.43 & 515.1182 & $\mathrm{C}_{25} \mathrm{H}_{23} \mathrm{O}_{12}$ & -0.587 & 353.08 & 3,4-Dicaffeoylquinic acid & $x$ & $x$ & $x$ & $x$ & [36] \\
\hline 15 & 12.47 & 563.1417 & $\mathrm{C}_{26} \mathrm{H}_{27} \mathrm{O}_{14}$ & 3.860 & - & $\begin{array}{l}\text { Apigenin-6-O-arabinoside-8- } \\
\text { O-glucoside }\end{array}$ & - & - & $x$ & - & [33] \\
\hline 16 & 12.89 & 515.1182 & $\mathrm{C}_{25} \mathrm{H}_{23} \mathrm{O}_{12}$ & 1.781 & 353.08 & 3,5-Dicaffeoylquinic acid & $x$ & $x$ & $x$ & $x$ & [36] \\
\hline 17 & 13.24 & 515.1187 & $\mathrm{C}_{25} \mathrm{H}_{23} \mathrm{O}_{12}$ & 0.248 & 353.08 & 4,5-Dicaffeoylquinic acid & $x$ & $x$ & $x$ & $x$ & [36] \\
\hline 18 & 13.40 & 447.0932 & $\mathrm{C}_{21} \mathrm{H}_{19} \mathrm{O}_{11}$ & 1.101 & - & Luteolin-7-O-glucoside & - & - & $x$ & - & [33] \\
\hline 19 & 14.09 & 695.1241 & $\mathrm{C}_{33} \mathrm{H}_{27} \mathrm{O}_{17}$ & 0.337 & $\begin{array}{l}533.09 / \\
371.06\end{array}$ & Tricaffeoylaltraricric acid & $x$ & $x$ & - & - & [39] \\
\hline 20 & 14.20 & 499.1237 & $\mathrm{C}_{25} \mathrm{H}_{23} \mathrm{O}_{11}$ & 0.585 & $\begin{array}{l}353.09 / \\
337.09 / \\
191.06\end{array}$ & $\begin{array}{c}\text { 3-p-(E)-Coumaroyl-5-(E)- } \\
\text { caffeoylquinic } \\
\text { acid }\end{array}$ & $x$ & - & - & $x$ & [34] \\
\hline 21 & 14.34 & 609.1602 & $\mathrm{C}_{27} \mathrm{H}_{29} \mathrm{O}_{16}$ & 1.010 & 301 & Rutin & - & - & $x$ & - & [33] \\
\hline 22 & 14.57 & 399.3621 & $\mathrm{C}_{28} \mathrm{H}_{47} \mathrm{O}$ & -0.107 & $\begin{array}{l}152.01 / \\
153.02 / \\
315.07\end{array}$ & Campesterol & - & - & $x$ & - & {$[30,31]$} \\
\hline 23 & 15.55 & 435.0920 & $\mathrm{C}_{20} \mathrm{H}_{19} \mathrm{O}_{11}$ & -0.340 & $\begin{array}{l}297.06 / \\
315.07\end{array}$ & Shimobashiraside C & $x$ & - & - & $x$ & {$[38,40]$} \\
\hline 24 & 15.95 & 411.3617 & $\mathrm{C}_{29} \mathrm{H}_{47} \mathrm{O}$ & -0954 & 315.07 & Stigmasterol & - & - & $x$ & - & {$[30,31]$} \\
\hline 25 & 16.07 & 577.1341 & $\mathrm{C}_{30} \mathrm{H}_{25} \mathrm{O}_{12}$ & 0.060 & 269.05 & $\begin{array}{l}\text { Apigenin-7- } \beta \text {-D-O- }(p- \\
\text { coumaroyl)-glucoside } \\
\text { isomer }\end{array}$ & - & - & $X$ & $x$ & {$[15,29]$} \\
\hline 26 & 16.17 & 357.1914 & $\mathrm{C}_{18} \mathrm{H}_{29} \mathrm{O}_{7}$ & 1.765 & 198.02 & Unknown & - & - & - & $x$ & - \\
\hline 27 & 16.42 & 582.2596 & $\mathrm{C}_{21} \mathrm{H}_{44} \mathrm{O}_{17} \mathrm{~N}$ & -1.360 & 462.20 & Unknown & - & - & $x$ & - & - \\
\hline 28 & 16.84 & 327.2174 & $\mathrm{C}_{18} \mathrm{H}_{31} \mathrm{O}_{5}$ & 2.290 & $\begin{array}{c}171.10 / \\
211.13 / \\
229.14 / \\
291.20\end{array}$ & 9,12,13-TriHODE $(10,15)$ & $x$ & $x$ & & $x$ & [32] \\
\hline 29 & 16.88 & 385.3458 & $\mathrm{C}_{27} \mathrm{H}_{45} \mathrm{O}$ & -1.610 & - & Cholesterol & - & - & $x$ & - & {$[30,31]$} \\
\hline 30 & 17.09 & 397.3451 & $\mathrm{C}_{28} \mathrm{H}_{45} \mathrm{O}$ & -3.501 & - & Brassicasterol & - & - & $x$ & - & {$[30,31]$} \\
\hline 31 & 17.16 & 519.1862 & $\mathrm{C}_{26} \mathrm{H}_{31} \mathrm{O}_{11}$ & 0.370 & $\begin{array}{c}213.09 / \\
475.20\end{array}$ & Unknown & - & $x$ & - & - & - \\
\hline 32 & 17.29 & 665.3169 & $\mathrm{C}_{34} \mathrm{H}_{49} \mathrm{O}_{13}$ & 0.289 & 503.29 & Unknown & $x$ & - & - & - & - \\
\hline 33 & 17.76 & 329.2330 & $\mathrm{C}_{18} \mathrm{H}_{33} \mathrm{O}_{5}$ & 2.276 & $\begin{array}{l}211.13 / \\
229.14\end{array}$ & 9,12,13-TriHODE (10) & $x$ & $x$ & - & - & [32] \\
\hline
\end{tabular}


Table 1. Cont.

\begin{tabular}{|c|c|c|c|c|c|c|c|c|c|c|c|}
\hline $\begin{array}{l}\text { Peak } \\
\text { No. }\end{array}$ & $\mathbf{R}_{\mathrm{t}}$ & {$[\mathbf{M}-\mathbf{H}]^{-}$} & $\begin{array}{l}\text { Molecular } \\
\text { Formula }\end{array}$ & $\Delta \mathrm{Ppm}$ & MS/MS & Identity & $\mathrm{S}$ & $\mathbf{R}$ & $\mathbf{F}$ & $\mathbf{L}$ & References \\
\hline 34 & 17.79 & 577.1343 & $\mathrm{C}_{30} \mathrm{H}_{25} \mathrm{O}_{12}$ & 0.491 & $\begin{array}{c}269.04 / \\
413.09 / \\
431.10\end{array}$ & $\begin{array}{l}\text { Apigenin-7- } \beta-\mathrm{D}-\mathrm{O}-(p- \\
\text { coumaroyl)-glucoside } \\
\text { isomer }\end{array}$ & - & - & $x$ & $x$ & {$[15,29]$} \\
\hline 35 & 17.90 & 609.1602 & $\mathrm{C}_{27} \mathrm{H}_{29} \mathrm{O}_{16}$ & 2.011 & - & Hesperidin & - & - & $x$ & - & {$[27,33]$} \\
\hline 36 & 18.26 & 579.1497 & $\mathrm{C}_{30} \mathrm{H}_{27} \mathrm{O}_{12}$ & 1.022 & $\begin{array}{l}271.06 / \\
307.08\end{array}$ & $\begin{array}{l}\text { Naringenin-coumaroyl- } \\
\text { glucoside }\end{array}$ & - & - & $x$ & $x$ & [27] \\
\hline 37 & 18.31 & 605.1866 & $\mathrm{C}_{29} \mathrm{H}_{33} \mathrm{O}_{14}$ & 0.271 & 561.20 & Unknown & - & $x$ & - & - & - \\
\hline 38 & 18.31 & 299.0556 & $\mathrm{C}_{16} \mathrm{H}_{11} \mathrm{O}_{6}$ & 1.990 & - & Hispidulin & - & $x$ & - & - & [27] \\
\hline 39 & 18.37 & 609.1603 & $\mathrm{C}_{27} \mathrm{H}_{29} \mathrm{O}_{16}$ & 2.010 & - & $\begin{array}{l}\text { Luteolin-Ara-Glu or } \\
\text { Luteolin-Glu-Ara }\end{array}$ & - & - & $x$ & - & {$[27,33]$} \\
\hline 40 & 18.62 & 619.1443 & $\mathrm{C}_{32} \mathrm{H}_{27} \mathrm{O}_{13}$ & -1.040 & 269 & Apigenin derivative & - & - & $x$ & $x$ & [27] \\
\hline 41 & 23.84 & 445.2431 & $\mathrm{C}_{22} \mathrm{H}_{37} \mathrm{O}_{9}$ & -0.178 & $\begin{array}{l}198.01 / \\
283.86\end{array}$ & Unknown & - & $x$ & - & - & - \\
\hline 42 & 26.56 & 761.2856 & $\mathrm{C}_{34} \mathrm{H}_{49} \mathrm{O}_{19}$ & -0.808 & $\begin{array}{l}198.00 / \\
283.86 / \\
633.24\end{array}$ & Unknown & - & $x$ & - & - & - \\
\hline 43 & 29.55 & 295.2273 & $\mathrm{C}_{18} \mathrm{H}_{31} \mathrm{O}_{3}$ & 2.096 & $\begin{array}{l}171.10 / \\
277.22\end{array}$ & $\begin{array}{l}\text { 10,12-Octadecadienoic acid, } \\
\text { 9-hydroxy- }\end{array}$ & - & $x$ & - & - & [27] \\
\hline 44 & 33.27 & 513.3062 & $\mathrm{C}_{27} \mathrm{H}_{45} \mathrm{O}_{9}$ & 0.781 & $\begin{array}{l}198.01 / \\
283.86\end{array}$ & Unknown & - & $x$ & - & - & - \\
\hline 45 & 36.98 & 271.0607 & $\mathrm{C}_{16} \mathrm{H}_{17} \mathrm{O}_{9}$ & 0.101 & - & Naringenin & - & - & $x$ & - & {$[27,33]$} \\
\hline
\end{tabular}

\subsection{Quantitative Determination of E. spinosus Major Phenolic Compounds Using HPLC-DAD}

Quantitative investigation of E. spinosus extracts was performed on targeted phenolic compounds, especially the caffeoylquinic acid derivatives, and the results are reported as $\mathrm{mg} / \mathrm{g}$ dried residue (Table 2). This is the first quantitative metabolite data report for E. spinosus. Among the monocaffeoyl quinic derivatives, the most abundant is chlorogenic acid (5-O-caffeoylquinic acid), which showed the highest content in the leaves estimated at $74.30 \pm 1.92 \mathrm{mg} / \mathrm{g}$ dried residue, in addition to the highest content of neochlorogenic acid (3-O-caffeoylquinic acid, $4.77 \pm 0.57 \mathrm{mg} / \mathrm{g}$ dried residue). Among the dicaffeoyl quinic acids, the dominant compounds are the isomers 3,5-dicaffeoylquinic (3,5-diCQ) and 4,5-dicaffeoylquinic (4,5-diCQ) acids, which together represented 50 to $72 \%$ of all the hydroxy cinnamic derivatives in the extracts of E. spinosus. It is interesting to note that the quantitative relationships between these two acids change according to the botanical part extracted. In the extracts of the stems, roots, and flowers, the 3,5-diCQ isomer is always similar or in a slightly greater concentration than the 4,5-diCQ isomer, whereas in the leaves the concentration of 4,5-diCQ acid is almost twice that of 3,5-diCQ acid (104.85 \pm 9.02 vs. $68.79 \pm 0.22 \mathrm{mg} / \mathrm{g}$ dried residue, respectively). Flavonoids were found to be most expressed in the flowers ( $21.32 \pm 0.08 \mathrm{mg} / \mathrm{g}$ dried residue), followed by the leaves $(8.55 \pm 0.07 \mathrm{mg} / \mathrm{g}$ dried residue) and roots $(3.98 \pm 0.21 \mathrm{mg} / \mathrm{g}$ dried residue), whereas traces were detected in the stems. The basic aglycones were typically apigenin, luteolin, naringenin, hesperetin, hispidulin, and quercetin. The dominant compounds in the flower and leaf extracts were hesperidin (hesperetin-7-rutinoside) and naringenin-coumaroylglucoside, the roots contained hispidulin, estimated by $3.98 \pm 0.21 \mathrm{mg} / \mathrm{g}$ dried residue, and in contrast, traces were detected in the stems. Among the hydroxybenzoic acid derivatives it was possible to identify a protocatechuic acid hexoside and shimobashiraside C. The former was particularly concentrated in the leaves and roots, with values estimated as $2.66 \pm 0.10$ and $2.90 \pm 0.08 \mathrm{mg} / \mathrm{g}$ dried residue, respectively, whereas the latter existed more in the leaves and stems, with values equal $2.86 \pm 0.09$ and $1.15 \pm 0.04 \mathrm{mg} / \mathrm{g}$ dried residue, respectively. 
Table 2. Concentration of targeted polar compounds ( $\mathrm{mg} / \mathrm{g}$ dried residue) in E. spinosus L. extracts (mean $\pm \mathrm{SD}, n=3$ ).

\begin{tabular}{|c|c|c|c|c|c|}
\hline \multirow{2}{*}{ Compound } & \multirow{2}{*}{ Identification $^{\text {a }}$} & \multicolumn{4}{|c|}{ Extract (mg/g Dried Residue) } \\
\hline & & Stems & Roots & Flowers & Leaves \\
\hline Hydroxy cinnamic acid derivatives & & $135.28 \pm 1.42$ & $330.20 \pm 0.98$ & $105.95 \pm 0.41$ & $284.86 \pm 2.9$ \\
\hline Neochlorogenic acid (NCGA, 3-CQA) & Rt, UV-Vis, MS & $1.54 \pm 0.22$ & $2.19 \pm 0.14$ & $1.51 \pm 0.07$ & $4.77 \pm 0.57$ \\
\hline Chlorogenic acid (CGA, 5-CQA) & Rt, UV-Vis, MS & $22.56 \pm 0.25$ & $46.01 \pm 0.56$ & $17.18 \pm 0.34$ & $74.30 \pm 1.92$ \\
\hline Dicaffeoyl altraric acid ${ }^{b}$ & UV-Vis, MS & $4.14 \pm 4.24$ & $35.95 \pm 0.02$ & $1.10 \pm 0.02$ & $3.83 \pm 0.12$ \\
\hline Dicaffeoylquinic acid (diCQA) ${ }^{b}$ & UV-Vis, MS & $2.71 \pm 0.13$ & $6.68 \pm 0.19$ & $0.29 \pm 0.01$ & $1.76 \pm 0.08$ \\
\hline 3,4-Dicaffeoylquinic acid ${ }^{b}$ & UV-Vis, MS & $4.58 \pm 0.01$ & $16.18 \pm 0.72$ & $10.34 \pm 0.01$ & $3.69 \pm 0.1$ \\
\hline 3,5-Dicaffeoylquinic acid & Rt, UV-Vis, MS & $44.13 \pm 2.69$ & $93.11 \pm 3.13$ & $45.50 \pm 1.25$ & $68.79 \pm 0.22$ \\
\hline 4,5-Dicaffeoylquinic acid ${ }^{b}$ & UV-Vis, MS & $40.57 \pm 1.15$ & $91.12 \pm 1.34$ & $29.26 \pm 0.54$ & $104.85 \pm 9.02$ \\
\hline Tricaffeoyl-altraric acid $^{\mathrm{b}}$ & UV-Vis, MS & $6.84 \pm 0.32$ & $38.97 \pm 1.32$ & $0.76 \pm 0.07$ & $5.94 \pm 0.5$ \\
\hline Coumaroyl-caffeoylquinic acid $^{\mathrm{c}}$ & UV-Vis, MS & $8.22 \pm 0.64$ & $\operatorname{tr}$ & $\operatorname{tr}$ & $17.44 \pm 0.34$ \\
\hline Flavonoids & & $\operatorname{tr}$ & $3.98 \pm 0.21$ & $21.32 \pm 0.08$ & $8.55 \pm 0.07$ \\
\hline $\begin{array}{l}\text { Apigenin-6-arabinoside-8- } \\
\text { galactoside }\end{array}$ & UV-Vis, MS & nd & nd & $1.87 \pm 0.01$ & nd \\
\hline Apigenin 6-arabinoside-8-glucoside ${ }^{\mathrm{d}}$ & UV-Vis, MS & nd & nd & $0.92 \pm 0.01$ & nd \\
\hline Luteolin-7-O-glucoside & Rt, UV-Vis, MS & $\operatorname{tr}$ & $\operatorname{tr}$ & $1.91 \pm 0.01$ & $\operatorname{tr}$ \\
\hline Quercetin-3-rutinoside (rutin) & Rt, UV-Vis, MS & nd & nd & $1.65 \pm 0.23$ & nd \\
\hline $\begin{array}{l}\text { Apigenin-7-O-( } p \text {-coumaroyl- } \\
\text { glucoside }) \text { isomer } \mathrm{d}\end{array}$ & UV-Vis, MS & $\operatorname{tr}$ & $\operatorname{tr}$ & $1.32 \pm 0.01$ & $3.68 \pm 0.05$ \\
\hline $\begin{array}{l}\text { Apigenin-7-O-( } p \text {-coumaroyl- } \\
\text { glucoside }) \text { isomer }{ }^{d}\end{array}$ & UV-Vis, MS & nd & nd & $1.81 \pm 0.01$ & $2.07 \pm 0.02$ \\
\hline Hesperetin-7-rutinoside (Hesperidin) & Rt, UV-Vis, MS & $\operatorname{tr}$ & $\operatorname{tr}$ & $3.00 \pm 0.07$ & $\operatorname{tr}$ \\
\hline Naringenin-coumaroyl-glucoside ${ }^{f}$ & UV-Vis, MS & $\operatorname{tr}$ & $\operatorname{tr}$ & $4.01 \pm 0.23$ & $1.36 \pm 0.02$ \\
\hline Hispidulin & Rt, UV-Vis, MS & $\operatorname{tr}$ & $3.98 \pm 0.21$ & nd & nd \\
\hline Luteolin ara-glu/glu-ara ${ }^{\mathrm{e}}$ & UV-Vis, MS & nd & nd & $0.94 \pm 0.03$ & nd \\
\hline Apigenin glucosidated $^{\mathrm{d}}$ & UV-Vis, MS & nd & nd & $3.02 \pm 0.02$ & $1.44 \pm 0.06$ \\
\hline Naringenin & Rt, UV-Vis, MS & nd & nd & $0.88 \pm 0.03$ & nd \\
\hline Hydroxybenzoic acid derivatives & & $2.46 \pm 0.001$ & $2.90 \pm 0.08$ & $0.93 \pm 0.02$ & $5.52 \pm 0.01$ \\
\hline Protocatecuic acid hexoside $\mathrm{g}$ & UV-Vis, MS & $1.31 \pm 0.04$ & $2.90 \pm 0.08$ & $0.93 \pm 0.02$ & $2.66 \pm 0.1$ \\
\hline Shimobashiraside $\mathrm{C}^{\mathrm{g}}$ & UV-Vis, MS & $1.15 \pm 0.04$ & $\operatorname{tr}$ & $\operatorname{tr}$ & $2.86 \pm 0.09$ \\
\hline
\end{tabular}

${ }^{a}$ : Rt, comparison with retention time of pure standard; UV-Vis, comparison with UV-VIS spectra of pure compound or similar pure standards; MS, MS/MS spectra fragmentation patterns reported in the literature as described in Table $1{ }^{\mathrm{b}}$ : Determined with the calibration curve of 3,5-dicaffeoylquinic acid. ${ }^{c}$ : Determined with the calibration curve of chlorogenic acid. ${ }^{d}$ : Determined with the calibration curve of apigenin-7-O-glucoside e: Determined with the calibration curve of luteolin-7-O-glucoside. ${ }^{\mathrm{f}}$ : Determined with the naringenin calibration curve. 8 : Determined with the protocatechuic acid calibration curve. The results are reported as mean value \pm standard deviation $(n=3)$; nd: not detected $(<\mathrm{LOD})$; tr, traces $(<\mathrm{LOQ})$.

A comparison of the metabolite profiles for the four plant parts revealed that the compounds occurring in all plant parts were protocatechuic acid hexoside and the caffeoylquinic acid derivatives, mainly chlorogenic acid, 3,5-dicaffeoylquinic acid, and 4,5-dicaffeoylquinic acid. These are 3,4-dihydroxycinnamic acid (HCA) derivatives, and their abundance is likely very important biologically. HCAs are considered significant from a nutritional point of view, owing to their antioxidant activities as catechols in addition to their protective effects against cancer and heart disease [45,46]. 


\subsection{Discrimination of the Different E. spinosus Organs Using Multivariate Data Analysis}

Chemometric analysis was performed by adopting unsupervised pattern recognition represented by principal component analysis (PCA) and hierarchical cluster analysis (HCA) based upon the qualitative and quantitative LC data (Figure 2). Principal component analysis (PCA) was primarily established to classify data and thus correlate the tested samples with the utilized variables [19].
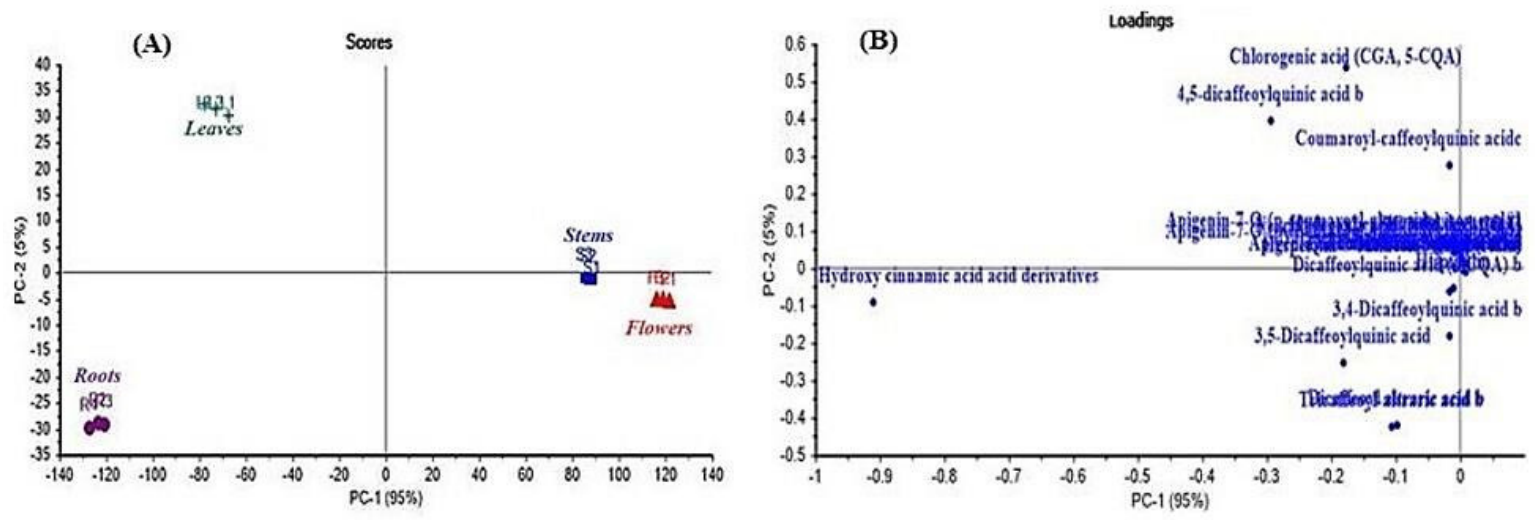

(C)

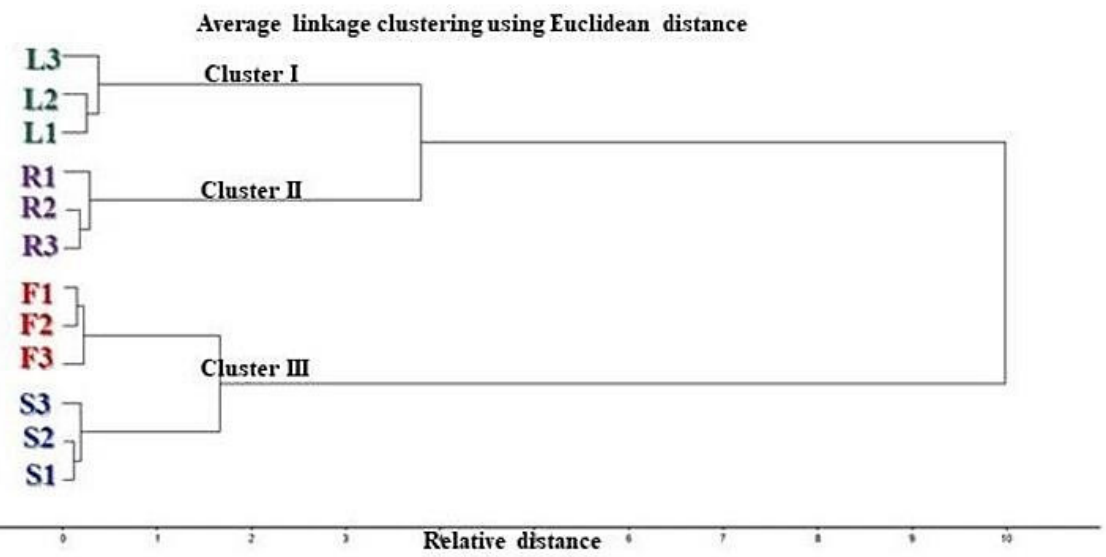

Figure 2. LC-based chemometrics analysis of different Echinopsis spinosus L. organs. (A) Score plot; (B) loading plot; (C) HCA.

The score plot illustrated in Figure 2A effectively discriminates different E. spinosus organs into three distinct clusters, wherein the stems and flowers are allocated in the same cluster, reflecting their resemblance in their secondary metabolites, which undoubtedly influence their bioactivity, in contrast to the leaves and roots, which appeared in distant clusters. The PCA score plot for principal components (PCs), which were PC1 versus PC2, accounted for $95 \%$ and $5 \%$ of the total variance, respectively. Both PCs significantly discriminated between leaves that in the upper left quadrant, showing negative values for $\mathrm{PC} 1$ and positive values for $\mathrm{PC} 2$, and stems and roots in the lower right quadrant, displaying positive values for PC1 and negative values for PC2. Meanwhile, PC1 effectively distinguished between roots in the lower left quadrant, displaying negative values, and between stems and flowers. Furthermore, PC2 differentiated between leaves (positive values) and roots (negative values). By comprehensive interpretation of the loading plot (Figure 2B), it can be concluded that hydroxy cinnamic acid derivatives, chlorogenic acid, 4,5-dicaffeoylquinic acid, and coumaroyl-caffeoylquinic acid represent the main discriminatory signals among the four organs. Furthermore, HCA clustering was done with the aim of ascertaining the results obtained from PCA, wherein samples were clustered into three clusters, as illustrated in the HCA dendrogram (Figure 2C). Both flowers and stems were clustered together (cluster III) with short distance between them, compared to the roots and leaves, which formed two clusters (clusters I and II). Thus, the HCA dendrogram 
further confirmed the results displayed by PCA, revealing the similarity between the stems and flowers, as evidenced by their clustering in one cluster.

\subsection{Determination of the Antioxidant Activity of E. spinosus Extracts}

The antioxidant activity was measured in vitro by employing the ferric reducing/antioxidant power (FRAP), cupric reducing antioxidant activity (CUPRAC), and free radical-scavenging activity (DPPH${ }^{\bullet}$ and $\mathrm{ABTS}^{\bullet+}$ ) assays for the E. spinosus extracts. The results of the performed assays, expressed based on g of dry residue, show approximately the same trends among the four examined extracts (Table 3). E. spinosus root extract exhibited the highest antioxidant activity, as evidenced by 3.26 and $1.61 \mathrm{mmol} \mathrm{Fe}{ }^{2+} / \mathrm{g}$ dried residue for CUPRAC and FRAP assays, respectively, as well as great free radical-scavenging activity potential, as estimated by values of 0.53 and $0.82 \mathrm{mmol} \mathrm{TEAC} / \mathrm{g}$ dried residue for $\mathrm{DPPH}^{\bullet}$ and $\mathrm{ABTS}^{\bullet+}$, respectively. In contrast, the stem extract exerted the least antioxidant activity, with a total antioxidant activity of 0.89 and $2.03 \mathrm{mmol} \mathrm{Fe} \mathrm{Fe}^{2+} / \mathrm{g}$ dried residue for FRAP and CUPRAC, respectively, and the free radical-scavenging activity was 0.37 and $0.47 \mathrm{mmol} \mathrm{TEAC} / \mathrm{g}$ dried residue for $\mathrm{DPPH}^{\bullet}$ and $\mathrm{ABTS}^{\bullet+}$, respectively. Flower and leaf extracts showed similar antioxidant values, in between those of the stems and roots, but closer to the stem values.

Table 3. Antioxidant capacities, total phenols, and total flavonoids of different E. spinosus extracts (per g of extract dry residue).

\begin{tabular}{cccccccc}
\hline Samples & CUPRAC $^{\mathbf{a}}$ & FRAP $^{\mathbf{a}}$ & DPPH $^{\bullet \mathbf{b}}$ & ABTS $^{\bullet+b}$ & TP $^{\mathbf{c}}$ & TF I $^{\mathbf{d}}$ & TF II $^{\mathbf{e}}$ \\
\hline Stems & $2.03 \pm 0.09^{\mathrm{a}}$ & $0.89 \pm 0.04^{\mathrm{a}}$ & $0.37 \pm 0.02^{\mathrm{a}}$ & $0.47 \pm 0.03^{\mathrm{ac}}$ & $83.60 \pm 3.64^{\mathrm{a}}$ & $10.64 \pm 1.63^{\mathrm{a}}$ & $105.41 \pm 2.79^{\mathrm{a}}$ \\
Roots & $3.26 \pm 0.19^{\mathrm{b}}$ & $1.61 \pm 0.14^{\mathrm{b}}$ & $0.53 \pm 0.01^{\mathrm{b}}$ & $0.82 \pm 0.04^{\mathrm{b}}$ & $125.16 \pm 9.48^{\mathrm{b}}$ & $25.40 \pm 1.76^{\mathrm{b}}$ & $140.12 \pm 1.48^{\mathrm{b}}$ \\
Flowers & $2.50 \pm 0.12^{\mathrm{c}}$ & $1.06 \pm 0.08^{\mathrm{c}}$ & $0.42 \pm 0.03^{\mathrm{ac}}$ & $0.52 \pm 0.02^{\mathrm{ac}}$ & $97.59 \pm 4.25^{\mathrm{c}}$ & $9.22 \pm 1.31^{\mathrm{a}}$ & $124.71 \pm 7.95^{\mathrm{c}}$ \\
Leaves & $2.37 \pm 0.30^{\mathrm{ac}}$ & $1.02 \pm 010^{\mathrm{ac}}$ & $0.47 \pm 0.02^{\mathrm{c}}$ & $0.46 \pm 0.02^{\mathrm{a}}$ & $121.50 \pm 11.25^{\mathrm{b}}$ & $13.15 \pm 0.73^{\mathrm{c}}$ & $138.10 \pm 1.94^{\mathrm{d}}$ \\
\hline
\end{tabular}

${ }^{a}$ FRAP (ferric ion-reducing antioxidant power) and CUPRAC (cupric ion-reducing antioxidant capacity) values are expressed as $\mathrm{Fe}^{2+}$ millimolar concentration, obtained from a $\mathrm{FeSO}_{4}$ solution with an antioxidant capacity equivalent to that of the dilution of the dry extract residue; $\mathrm{mmol} \mathrm{Fe}^{2+} / \mathrm{g}$ dried residue. ${ }^{\mathrm{b}} \mathrm{DPPH}^{\bullet}$ (1.1-diphenyl2-picrylhydrazylradical) and $\mathrm{ABTS}^{\bullet+}\left(2.2^{\prime}\right.$-azino-bis(3-ethylbenzothiazoline-6-sulfonate radical cation) values are expressed as TEAC millimolar concentration, obtained from a Trolox solution with an antiradical capacity equivalent to that of the dilution of the dry extract residue; mmol TEAC/g dried residue. ${ }^{\mathrm{c}} \mathrm{GAE}$ : gallic acid equivalent; mg GAE/g dried residue. ${ }^{\mathrm{d}} \mathrm{QE}$ : quercetin equivalent; $\mathrm{mg} \mathrm{QE} / \mathrm{g}$ dried residue. ${ }^{\mathrm{e}} \mathrm{CE}$ : catechin equivalent; $\mathrm{mg} \mathrm{CE} / \mathrm{g}$ dried residue. Results are reported as the mean value \pm standard deviation $(n=3)$. Means in the same column that do not share a letter are significantly different $(p \leq 0.05)$.

\subsection{Determination of the Total Phenolic and Flavonoid Contents of E. spinosus Extracts}

The total polyphenol (TP) and the total flavonoid (TF) contents were determined that strongly correlated with the results of the antioxidant activity. The roots showed the highest phenolic and flavonoid contents, estimated by $125.16 \mathrm{mg}$ GAE/g dried residue, $140.12 \mathrm{mg}$ CE/g dried residue, and $25.40 \mathrm{mg} \mathrm{QE} / \mathrm{g}$ dried residue for TP, TF II, and TF I, respectively. Meanwhile, the stem extract revealed the lowest in TP and TF II, estimated by $83.60 \mathrm{mg}$ GAE/g dried residue and $105.41 \mathrm{mg} \mathrm{CE} / \mathrm{g}$ dried residue, respectively. Furthermore, the flowers showed the lowest level of flavonoids, with TF I equal to $9.22 \mathrm{mg} Q \mathrm{QE} / \mathrm{g}$ dried residue. Good positive correlations were observed between the TP content measured by the Folin-Ciocalteu method and the four antioxidant activity values and was statistically significant $(p \leq 0.05)$ with $\mathrm{DPPH}^{\bullet}(r=0.9577)$. In addition, a good correlation was observed between all the antioxidant activity assays and the TF content and was statistically significant $(p \leq 0.05)$ for TFI/FRAP $(r=0.9464)$. Finally, it was observed that the TP content was significantly correlated with the total TF II $(r=0.9751)$. Direct comparison of the obtained results with the literature on E. spinosus, as well as other Echinops species, is not straightforward due to the different plant parts investigated and the extracting solvents used [47]. E. spinosus roots collected from Tunisia extracted with different solvents (ethanol, chloroform, hexane, and ethyl acetate) were examined for their investigated $\mathrm{TP}$ and $\mathrm{TF}$, as well as $\mathrm{DPPH}^{\bullet}$ antioxidant activity. It was shown that the TP, TF, and antioxidant activity highly relied upon the solvent polarity, and as expected, ethanol extracts were rich in 
phenolics compared to non-polar extracts. Moreover, the ethanol and methanol extracts of the leaves and seeds of E. ritro L. and E. tournefortii Ledeb were evaluated for their TP content and antioxidant activity. For both Echinops species, the methanol extracts showed the highest TP content and antioxidant activity measured by the $\mathrm{DPPH}^{\bullet}$ assay. These findings support the choice in this investigation to extract E. spinosus with a hydro-alcohol mixture. The ethanol extract of E. spinosus roots showed lower values for TP, TF, and DPPH ${ }^{\bullet}$ antioxidant activity than previously demonstrated by Khedher et al. [47]. Furthermore, a previous investigation of the hydroalcoholic extracts $\left(\mathrm{MeOH}: \mathrm{H}_{2} \mathrm{O}, 70: 30 v / v\right)$ of the aerial and root parts of E. spinosus revealed the presence of $36.1 \mathrm{mg}$ EAG/100 g dry matter and $13.37 \mathrm{mg}$ EC/100 $\mathrm{g}$ dry matter of TP and TF, respectively, in the aerial parts, and the roots contained $16.1 \mathrm{mg}$ EAG/100 g dry matter of TP and $4.78 \mathrm{mg}$ EC/100 g dry matter of TF [48]. A study performed on $70 \%$ ethanol extracts of E. spinosus above-ground parts growing in Egypt revealed lower values of TP, TF, and antioxidant activity [49], which may have been attributed to the difference in geographical region, the solvent used, and the extraction procedure, whereas in the current study an effective ultrasound-assisted extraction was performed twice.

\subsection{Computer-Aided Drug Design Studies}

\subsubsection{Molecular Docking}

In silico molecular modeling for the major polyphenolic compounds identified from different organs of E. spinosus methanol extract was done within the active sites of NADPH oxidase (NO) and myeloperoxidase (MP), which are responsible for the generation of reactive oxygen species (ROS), to estimate their enzymatic inhibitory potential. The results illustrated in Table 4 reveal that most of the tested compounds showed inhibition to both enzymes with varying degrees; however, tricaffeoyl-altraric acid followed by dicaffeoylaltraric acid exhibited the best fit within the active site of NADPH oxidase (NO) and myeloperoxidase $(\mathrm{MP})$, displaying binding energies $(\Delta \mathrm{G})$ of -93.93 and $-81.80 \mathrm{Kcal} / \mathrm{mol}$, respectively, for NADPH oxidase (NO), and $\Delta \mathrm{G}$ ) of -75.35 and $-60.52 \mathrm{Kcal} / \mathrm{mol}$, respectively, for myeloperoxidase (MP). This firm fitting within the active site of the enzymes can be explained by the virtue of the formation of many bonds. Concerning NADPH oxidase (NO), tricaffeoyl-altraric acid formed 13 conventional H-bonds with Asp282, Lys134, Ser41, Asn34, Asn36, Glu32, Ala11, Csx42, Gly329, and Leu299; one $\pi$-alkyl bond with Glu114; and one $\mathrm{C}-\mathrm{H}$ bond with Gly7 existing at the active site, together with many Van der Waals interactions (Figure 3A). Meanwhile, dicaffeoyl-altraric formed nine conventional H-bonds with Asp282, Glu163, Ala45, Lys134, His 10, ALa300, and Pro 298; two $\pi$-alkyl bonds with Ile44 and Ile160; one $\pi$-anion bond with Glu32; two $\pi$-sulfur bonds with Met33 and Cys133; one C-H bond with Leu299; and many Van der Waals interactions (Figure 3B).

Regarding myeloperoxidase (MP), tricaffeoyl-altraric acid formed eight H-bonds with His554, Gln483, Met479, Asp447, Aasn478, Gln420, and Gln452; one $\pi-\pi$ T-shaped bond with Tyr477; a $\pi$-alkyl bond with Leu535; two $\pi$-sulfur bonds with Met33; and one C-H bond with Gly466, together with the formation of multiple Van der Waals interactions (Figure 4A). However, dicaffeoyl-altraric formed seven H-bonds with Asp474, Thr90, Gln419, Gln420, Ser396, Tyr543, and Trp472; one $\pi-\pi$ T-shaped bond with Phe397; one C-H bond with Thr421; and many Van der Waals interactions (Figure 4B). The results of molecular docking further support the obtained in vitro results, wherein both tricaffeoyl-altraric acid and dicaffeoyl-altraric acid existed in a higher concentration in the roots, estimated at 38.97 and $46.01 \mathrm{mg} / \mathrm{g}$ dried residue, respectively, compared to other organs and showed the highest antioxidant capacity, as revealed in all the performed assays.

\subsubsection{ADME/TOPAKT Prediction}

E. spinosus major phenolic compounds were subjected to ADME/TOPAKT evaluations to assess their pharmacokinetic, pharmacodynamic, and toxicity properties in silico using Discovery Studio 4.5 (Accelrys Inc., San Diego, CA, USA). The results presented in Table 5 show that all the examined compounds displayed low human intestinal absorption except 
for hispidulin and naringenin, which showed good human intestinal absorption and hence were allocated inside the 95\% absorption ellipse, as revealed in the ADMET plot (Figure 5). Besides, most of the tested compounds showed low to very low solubility, except for naringenin, hispidulin, luteolin-7-O-glucoside, and coumaroyl-caffeoylquinic acid, which displayed good solubility. Meanwhile, chlorogenic acid and neochlorogenic acid showed optimal solubility. With respect to BBB, all the compounds showed undefined BBB, taking value 4 and appearing outside the $99 \%$ confidence eclipse of $\mathrm{BBB}$, whereas hispidulin and naringenin revealed low penetration via BBB and thus appeared within the $99 \%$ confidence eclipse of BBB in the ADMET plot. Furthermore, all the tested compounds showed less than $90 \%$ plasma protein binding (PPB). None of the tested compounds inhibited CPY2D6 except for apigenin 6-arabinoside-8-glucoside and naringenin, which displayed certain inhibitory potential versus CPY2D6. Regarding hepatotoxicity, apigenin 6-arabinoside-8-glucoside, hesperidin, hispidulin, luteolin-7-O-glucoside, naringenin, and rutin showed a certain degree of toxicity to hepatocytes, whereas other compounds revealed no hepatotoxicity.

Table 4. Binding energies $(\mathrm{kcal} / \mathrm{mol})$ of the major polar compounds in the E. spinosus L. extracts within the active sites of NADPH oxidase (NO) and myeloperoxidase (MP).

\begin{tabular}{|c|c|c|c|c|}
\hline Compounds & $\begin{array}{l}\text { NADPH Oxidase } \\
\text { (NO) }\end{array}$ & $\begin{array}{l}\text { Number of Formed } \\
\text { Hydrogen Bonds with the } \\
\text { Amino Acid Residues }\end{array}$ & $\begin{array}{l}\text { Myeloperoxidase } \\
\text { (MP) }\end{array}$ & $\begin{array}{l}\text { Number of Formed } \\
\text { Hydrogen Bonds with the } \\
\text { Amino Acid Residues }\end{array}$ \\
\hline $\begin{array}{l}\text { Apigenin } \\
\text { 6-arabinoside-8- } \\
\text { glucoside }\end{array}$ & 11.64 & $\begin{array}{c}\text { 7; Asp282, Glu163, Ala45, } \\
\text { Lys134, Csx } 42\end{array}$ & -1.44 & 4; Met422, Gln420, Gly493 \\
\hline $\begin{array}{l}\text { Apigenin-6- } \\
\text { arabinoside-8- } \\
\text { galactoside }\end{array}$ & -5.06 & $\begin{array}{c}\text { 6; Asp282, Glu163, Lys134, } \\
\text { Ser } 115\end{array}$ & 14.14 & $\begin{array}{c}\text { 5; Gly476, Asp447, Met479, } \\
\text { Gln452 }\end{array}$ \\
\hline Chlorogenic acid & -40.01 & $\begin{array}{c}\text { 7; Lys134, Ser115, Asn34, } \\
\text { Asn36, Tyr } 136\end{array}$ & -36.55 & $\begin{array}{c}\text { 6; Asp447, Asp474, Gly476, } \\
\text { Gln420, Met422 }\end{array}$ \\
\hline $\begin{array}{c}\text { Coumaroyl- } \\
\text { caffeoylquinic acid }\end{array}$ & -60.80 & $\begin{array}{c}\text { 5; Asp282, Lys134, Csx42, } \\
\text { His 10, Ala11 }\end{array}$ & -44.42 & $\begin{array}{l}\text { 6; ; Asp447, Asp474, Met479. } \\
\text { Gln482, Lys487, Glu484 }\end{array}$ \\
\hline $\begin{array}{l}\text { Dicaffeoyl } \\
\text { altraric acid }\end{array}$ & -81.8 & $\begin{array}{c}\text { 9; Asp282, Glu163, Ala45, } \\
\text { Lys134, His 10, } \\
\text { ALa300, Pro 298 }\end{array}$ & -60.52 & $\begin{array}{c}\text { 7; Asp474, Thr90, Gln419, } \\
\text { Gln420, Ser396, } \\
\text { Tyr543, Trp472 }\end{array}$ \\
\hline Dicaffeoylquinic acid & -58.16 & $\begin{array}{c}\text { 5; Asp282, Glu32, Lys134, } \\
\text { Ile 160, Csx42 }\end{array}$ & -49.41 & $\begin{array}{c}\text { 4; ; Asp447, Asp474, Ser396, } \\
\text { Gln19, Gln420 }\end{array}$ \\
\hline Hesperidin & -11.43 & $\begin{array}{c}\text { 5; Lys134, Asn135, Thr9, } \\
\text { Thr112, Ala11 }\end{array}$ & -4.23 & 2; Gln420, Met479 \\
\hline Hispidulin & -37.67 & 2; Asp282 & -30.34 & 3; Asp474, Gln420, Gly476 \\
\hline $\begin{array}{l}\text { Luteolin-7-O- } \\
\text { glucoside }\end{array}$ & -33.70 & $\begin{array}{l}\text { 7; Asp282, Lys134, Pro 298, } \\
\text { Csx42, ALa300, Glu32 }\end{array}$ & -15.23 & $\begin{array}{c}\text { 5; Asp447, Asp474, Gln420, } \\
\text { Gly476, Tyr543 }\end{array}$ \\
\hline $\begin{array}{c}\text { Naringenin- } \\
\text { coumaroyl-glucosid }\end{array}$ & -38.22 & $\begin{array}{c}\text { 6; Ala45, Ser41, Lys134, } \\
\text { Asn34, Asp282 }\end{array}$ & -23.75 & 2; Asp474, Tyr543 \\
\hline Naringenin & -36.05 & 3; Asp282, Glu32 & -30.90 & 3; Asp447, Asp474, Gly476 \\
\hline Neochlorogenic acid & -42.63 & $\begin{array}{c}\text { 6; Asp282, Lys134, Pro 298, } \\
\text { ALa300, Glu32 }\end{array}$ & -37.49 & $\begin{array}{c}\text { 5; Asp447, Asp474, Gln420, } \\
\text { Gln483, Ser396 }\end{array}$ \\
\hline Rutin & -12.13 & $\begin{array}{l}\text { 8; Asp282, Lys134, Pro 298, } \\
\text { Ser41, Asn34, Asn36, Met33 }\end{array}$ & 2.41 & 3; Asp447, Thr421, Gln419 \\
\hline $\begin{array}{l}\text { Tricaffeoyl- } \\
\text { altraric acid }\end{array}$ & -93.93 & $\begin{array}{l}\text { 13; Asp282, Lys134, Ser41, } \\
\text { Asn34, Asn36, Glu32, Ala11, } \\
\text { Csx42, Gly329, Leu299 }\end{array}$ & -75.35 & $\begin{array}{c}\text { 8; His554, Gln483, Met479, } \\
\text { Asp447, Aasn478, } \\
\text { Gln420, Gln452 }\end{array}$ \\
\hline
\end{tabular}



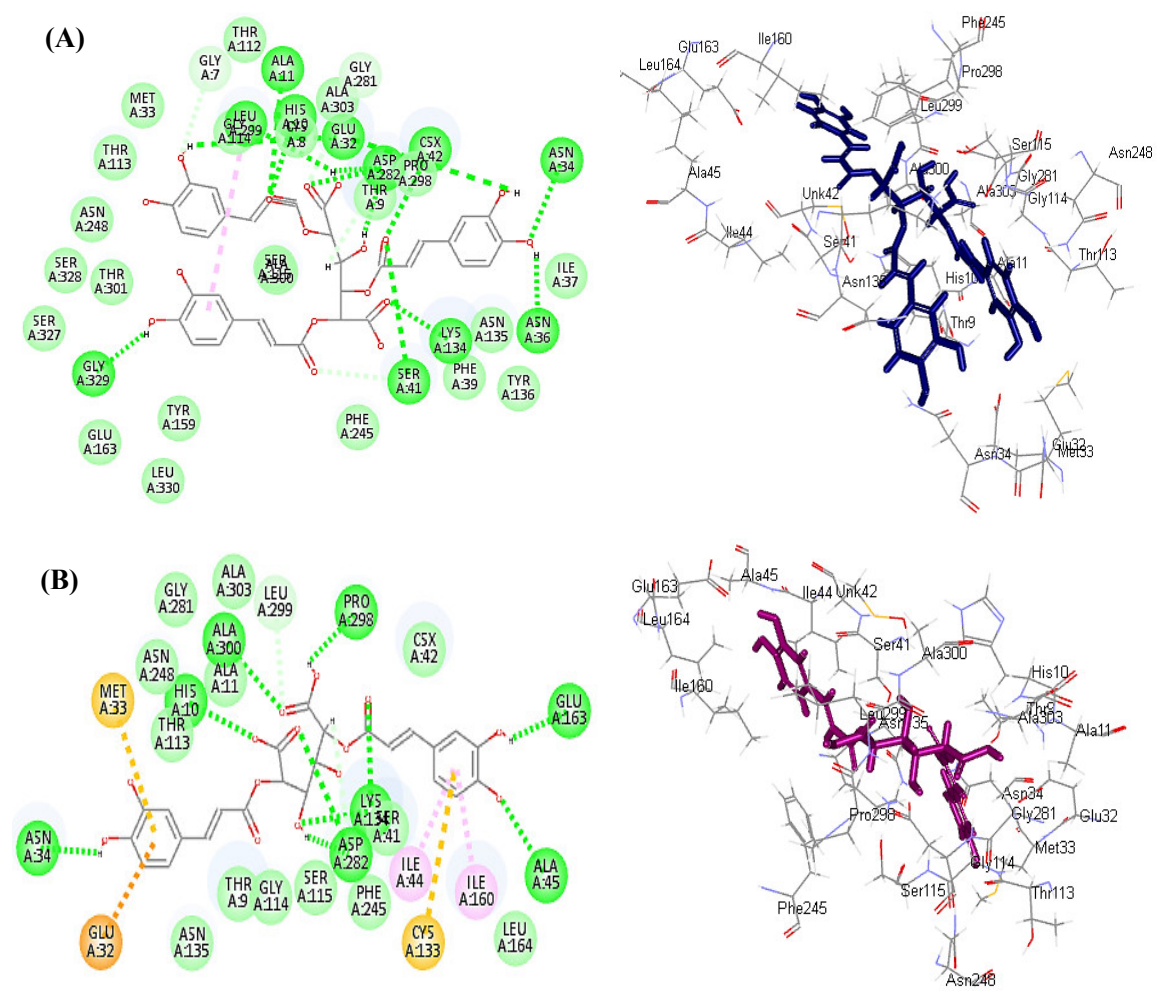

Figure 3. 2D and 3D binding mode of tricaffeoyl-altraric acid (A) and dicaffeoyl-altraric acid (B) identified in different Echinopsis spinosus L. organs in the binding site of NADPH oxidase (NO).
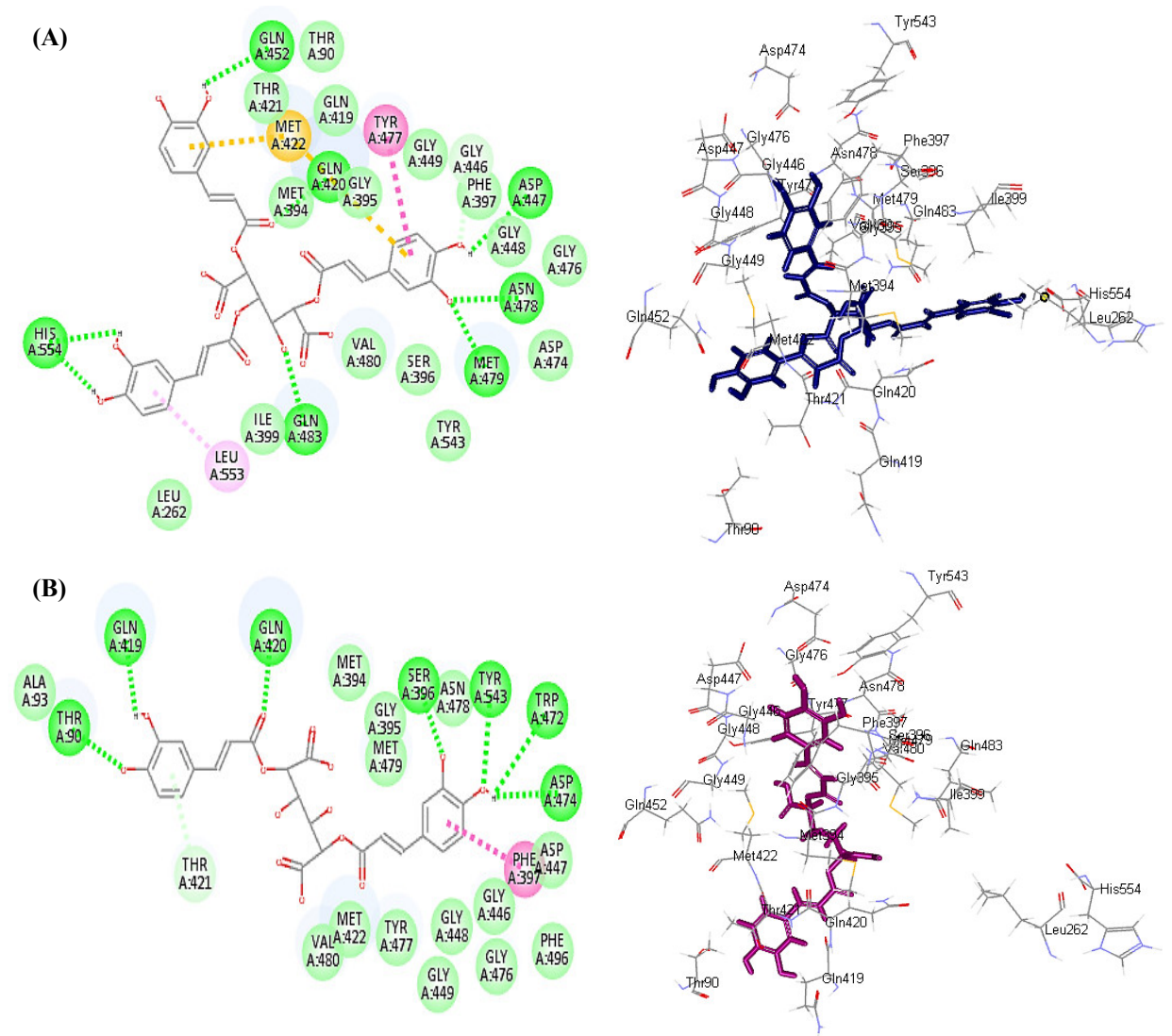

Figure 4. 2D and 3D binding mode of tricaffeoyl-altraric acid (A) and dricaffeoyl-altraric acid (B) identified in different Echinopsis spinosus L. organs in the binding site of myeloperoxidase (MP). 


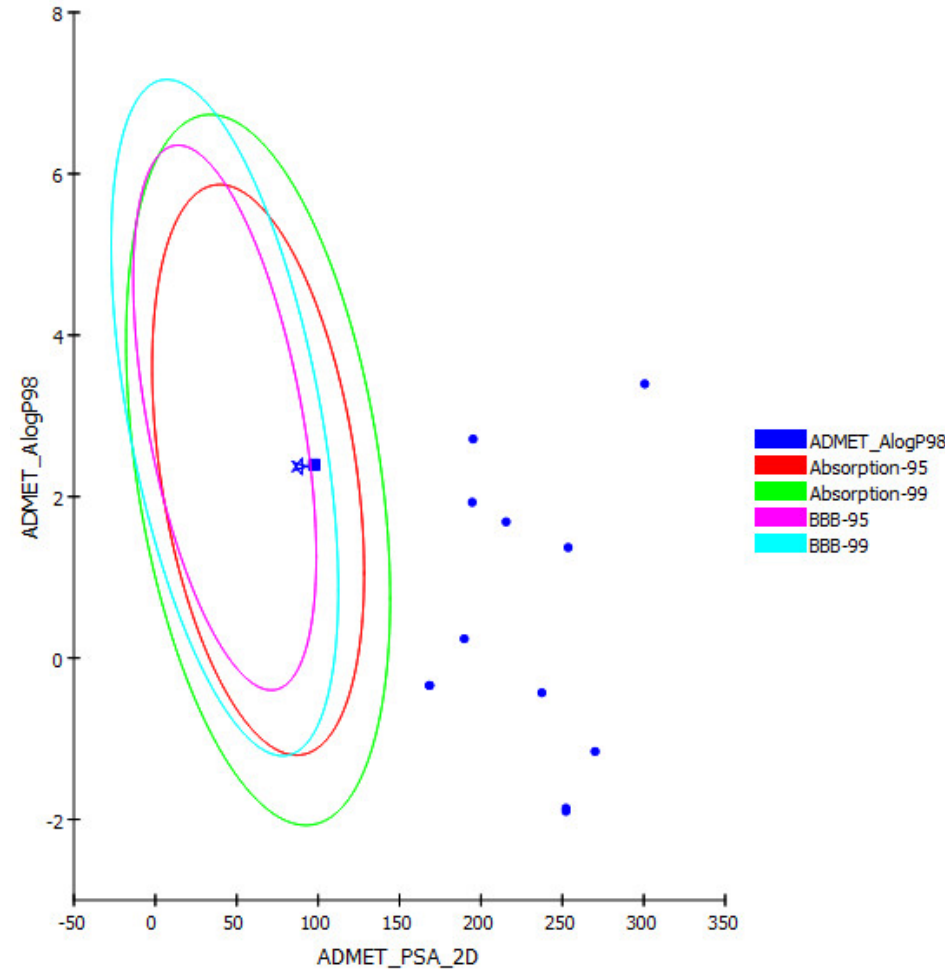

Figure 5. ADMET plot of E. spinosus major phenolic compounds displaying $95 \%$ and $99 \%$ confidence limit ellipses with respect to the human intestinal absorption and the blood-brain barrier (BBB) models; hispidulin (filled square); naringenin (filled star).

Table 5. ADMET (absorption, distribution, metabolism, excretion, and toxicity) properties of $E$. spinosus major phenolic compounds.

\begin{tabular}{|c|c|c|c|c|c|c|c|c|}
\hline Compounds & $\begin{array}{c}\text { Absorption } \\
\text { Level }\end{array}$ & $\begin{array}{c}\text { Solubility } \\
\text { Level }\end{array}$ & $\begin{array}{c}\text { BBB } \\
\text { Level }\end{array}$ & $\begin{array}{c}\text { PPB } \\
\text { Level }\end{array}$ & CPY2D6 & Hepatotoxic & PSA-2D & Alog p98 \\
\hline $\begin{array}{l}\text { Apigenin 6-arabinoside- } \\
\text { 8-glucoside }\end{array}$ & 3 & 2 & 4 & False & Inh. & Toxic & -1.90 & 252.25 \\
\hline $\begin{array}{l}\text { Apigenin-6- } \\
\text { arabinoside-8- } \\
\text { galactoside }\end{array}$ & 3 & 2 & 4 & False & NI & NT & -1.86 & 252.25 \\
\hline Chlorogenic acid & 3 & 4 & 4 & False & NI & NT & -0.34 & 168.42 \\
\hline $\begin{array}{c}\text { Coumaroyl- } \\
\text { caffeoylquinic acid }\end{array}$ & 3 & 3 & 4 & False & NI & NT & 1.93 & 194.66 \\
\hline Dicaffeoyl altraric acid & 3 & 2 & 4 & False & $\mathrm{NI}$ & NT & 1.37 & 253.59 \\
\hline Dicaffeoylquinic acid & 3 & 2 & 4 & False & NI & NT & 1.69 & 215.47 \\
\hline Hesperidin & 3 & 2 & 4 & False & $\mathrm{NI}$ & Toxic & -0.43 & 237.41 \\
\hline Hispidulin & 0 & 3 & 3 & False & NI & Toxic & 2.39 & 97.61 \\
\hline Luteolin-7-O-glucoside & 3 & 3 & 4 & False & $\mathrm{NI}$ & Toxic & 0.24 & 189.80 \\
\hline $\begin{array}{l}\text { Naringenin-coumaroyl- } \\
\text { glucosid }\end{array}$ & 3 & 2 & 4 & False & NI & NT & 2.71 & 195.21 \\
\hline Naringenin & 0 & 3 & 3 & False & Inh. & Toxic & 2.37 & 88.68 \\
\hline Neochlorogenic acid & 3 & 4 & 4 & False & NI & NT & -0.34 & 168.42 \\
\hline Rutin & 3 & 1 & 4 & False & $\mathrm{NI}$ & Toxic & -1.16 & 270.11 \\
\hline Tricaffeoyl-altraric acid & 3 & 1 & 4 & False & NI & NT & 3.40 & 300.63 \\
\hline
\end{tabular}

$0,1,2$, and 3 indicate good, moderate, low, and very low absorption, respectively; $0,1,2,3,4$, and 5 indicate extremely low, very low but possible, low, good, optimal, and too soluble, respectively; $0,1,2,3$, and 4 denote very high, high, medium, low, and undefined penetration via $\mathrm{BBB}$, respectively. PBB, plasma protein binding; false $=$ less than $90 \%$, true $=$ more than $90 \%$; NI: non-inhibitor; Inh.; inhibitor; NT: non-toxic. 
Concerning the TOPKAT evaluation, all the tested compounds showed a non-mutagenic effect, as evidenced by the Ames prediction. They also exerted no carcinogenic effect towards either male or female rat NTP, except for apigenin-6-arabinoside-8-galactoside, hispidulin, and naringenin, which showed a certain degree of carcinogenic effect versus male rat NTP only. In addition, the tested E. spinosus major phenolic compounds showed rat oral LD50 values in the range of 0.47 and $11.14 \mathrm{~g} / \mathrm{kg}$ body wt. Meanwhile, they displayed rat inhalational $\mathrm{LD}_{50}$ values ranging between 1.79 and $3435.69 \mathrm{mg} / \mathrm{m}^{3} / \mathrm{h}$ with LOAEL (lowest-observed-adverse-effect level) values between 0.01 and $0.27 / \mathrm{kg}$ body wt. None of the tested compounds revealed irritation to the skin. However, most of the compounds showed mild to moderate eye irritation, except for naringenin-coumaroylglucoside, which exhibited no irritation, in contrast to apigenin 6-arabinoside-8-glucoside, apigenin-6-arabinoside-8-galactoside, dicaffeoyl altraric acid, and tricaffeoyl-altraric acid, which revealed severe ocular irritancy. Moreover, naringenin was the only compound among all the tested E. spinosus major phenolic compounds that revealed aerobic nonbiodegradable behavior (Table 6).

Table 6. TOPKAT prediction of E. spinosus major phenolic compounds.

\begin{tabular}{|c|c|c|c|c|c|c|c|c|c|}
\hline Compounds & $\begin{array}{c}\text { Ames } \\
\text { Prediction }\end{array}$ & $\begin{array}{l}\text { Rat Oral } \\
\text { LD }_{50}\end{array}$ & $\begin{array}{l}\text { Rat Inhala- } \\
\text { tional } \\
\text { LD }_{50}\end{array}$ & $\begin{array}{l}\text { Rat } \\
\text { Chronic } \\
\text { LOAEL }\end{array}$ & $\begin{array}{c}\text { Skin } \\
\text { Irritancy }\end{array}$ & $\begin{array}{l}\text { Ocular } \\
\text { Irritancy }\end{array}$ & $\begin{array}{l}\text { Rat Female } \\
\text { NTP }\end{array}$ & $\begin{array}{l}\text { Rat Male } \\
\text { NTP }\end{array}$ & $\begin{array}{c}\text { Aerobic } \\
\text { Biodegrad- } \\
\text { ability }\end{array}$ \\
\hline $\begin{array}{l}\text { Apigenin } \\
\text { 6-arabinoside-8- } \\
\text { glucoside }\end{array}$ & $\begin{array}{l}\text { Non- } \\
\text { mutagen }\end{array}$ & 3.88 & 10.20 & 0.12 & None & Severe & $\begin{array}{l}\text { Non- } \\
\text { carcinogen }\end{array}$ & $\begin{array}{l}\text { Non- } \\
\text { carcinogen }\end{array}$ & Degradable \\
\hline $\begin{array}{l}\text { Apigenin-6- } \\
\text { arabinoside-8- } \\
\text { galactoside }\end{array}$ & $\begin{array}{l}\text { Non- } \\
\text { mutagen }\end{array}$ & 1.96 & 7.20 & 0.06 & None & Severe & $\begin{array}{l}\text { Non- } \\
\text { carcinogen }\end{array}$ & Carcinogen & Degradable \\
\hline Chlorogenic acid & $\begin{array}{l}\text { Non- } \\
\text { mutagen }\end{array}$ & 1.97 & 93.17 & 0.03 & None & Moderate & $\begin{array}{c}\text { Non- } \\
\text { carcinogen }\end{array}$ & $\begin{array}{c}\text { Non- } \\
\text { carcinogen }\end{array}$ & Degradable \\
\hline $\begin{array}{l}\text { Coumaroyl- } \\
\text { caffeoylquinic } \\
\text { acid }\end{array}$ & $\begin{array}{l}\text { Non- } \\
\text { mutagen }\end{array}$ & 1.70 & 33.23 & 0.02 & None & Moderate & $\begin{array}{l}\text { Non- } \\
\text { carcinogen }\end{array}$ & $\begin{array}{l}\text { Non- } \\
\text { carcinogen }\end{array}$ & Degradable \\
\hline $\begin{array}{c}\text { Dicaffeoyl altraric } \\
\text { acid }\end{array}$ & $\begin{array}{l}\text { Non- } \\
\text { mutagen }\end{array}$ & 7.98 & 9.59 & 0.27 & None & Severe & $\begin{array}{l}\text { Non- } \\
\text { carcinogen }\end{array}$ & $\begin{array}{l}\text { Non- } \\
\text { carcinogen }\end{array}$ & Degradable \\
\hline $\begin{array}{l}\text { Dicaffeoylquinic } \\
\text { acid }\end{array}$ & $\begin{array}{l}\text { Non- } \\
\text { mutagen }\end{array}$ & 2.06 & 19.41 & 0.02 & None & Moderate & $\begin{array}{l}\text { Non- } \\
\text { carcinogen }\end{array}$ & $\begin{array}{l}\text { Non- } \\
\text { carcinogen }\end{array}$ & Degradable \\
\hline Hesperidin & $\begin{array}{c}\text { Non- } \\
\text { mutagen }\end{array}$ & 2.89 & 39.63 & 0.05 & None & Mild & $\begin{array}{c}\text { Non- } \\
\text { carcinogen }\end{array}$ & $\begin{array}{c}\text { Non- } \\
\text { carcinogen }\end{array}$ & Degradable \\
\hline Hispidulin & $\begin{array}{l}\text { Non- } \\
\text { mutagen }\end{array}$ & 0.47 & 3646.74 & 0.06 & None & Moderate & $\begin{array}{c}\text { Non- } \\
\text { carcinogen }\end{array}$ & Carcinogen & $\begin{array}{c}\text { Non- } \\
\text { degradable }\end{array}$ \\
\hline $\begin{array}{l}\text { Luteolin-7-O- } \\
\text { glucoside }\end{array}$ & $\begin{array}{l}\text { Non- } \\
\text { mutagen }\end{array}$ & 1.36 & 100.48 & 0.03 & None & Moderate & $\begin{array}{c}\text { Non- } \\
\text { carcinogen }\end{array}$ & $\begin{array}{c}\text { Non- } \\
\text { carcinogen }\end{array}$ & Degradable \\
\hline $\begin{array}{l}\text { Naringenin- } \\
\text { coumaroyl- } \\
\text { glucosid }\end{array}$ & $\begin{array}{l}\text { Non- } \\
\text { mutagen }\end{array}$ & 2.46 & 72.35 & 0.01 & None & None & $\begin{array}{l}\text { Non- } \\
\text { carcinogen }\end{array}$ & $\begin{array}{l}\text { Non- } \\
\text { carcinogen }\end{array}$ & Degradable \\
\hline Naringenin & $\begin{array}{c}\text { Non- } \\
\text { mutagen }\end{array}$ & 1.58 & 3435.69 & 0.08 & None & Mild & $\begin{array}{c}\text { Non- } \\
\text { carcinogen }\end{array}$ & Carcinogen & $\begin{array}{c}\text { Non- } \\
\text { degradable }\end{array}$ \\
\hline $\begin{array}{l}\text { Neochlorogenic } \\
\text { acid }\end{array}$ & $\begin{array}{l}\text { Non- } \\
\text { mutagen }\end{array}$ & 1.97 & 93.17 & 0.03 & None & Moderate & $\begin{array}{c}\text { Non- } \\
\text { carcinogen }\end{array}$ & $\begin{array}{c}\text { Non- } \\
\text { carcinogen }\end{array}$ & Degradable \\
\hline Rutin & $\begin{array}{c}\text { Non- } \\
\text { mutagen }\end{array}$ & 2.01 & 14.28 & 0.10 & None & Mild & $\begin{array}{c}\text { Non- } \\
\text { carcinogen }\end{array}$ & Carcinogen & Degradable \\
\hline $\begin{array}{l}\text { Tricaffeoyl-altraric } \\
\text { acid }\end{array}$ & $\begin{array}{l}\text { Non- } \\
\text { mutagen }\end{array}$ & 11.14 & 1.79 & 0.22 & None & Severe & $\begin{array}{l}\text { Non- } \\
\text { carcinogen }\end{array}$ & $\begin{array}{l}\text { Non- } \\
\text { carcinogen }\end{array}$ & Degradable \\
\hline
\end{tabular}

Both rat chronic LOAEL and rat oral LD50 are measured in $\mathrm{g} / \mathrm{kg}$ bw; meanwhile, rat inhalational LD50 is measured in $\mathrm{mg} / \mathrm{m}^{3} / \mathrm{h}$.

From the ADME/TOPAKT analyses, it can be concluded that most of the compounds revealed acceptable toxicity properties. However, the pharmacokinetics and pharmacodynamics require some treatment to be suitable for incorporation into pharmaceutical dosage forms. It is worth highlighting that tricaffeoyl-altraric acid and dicaffeoyl-altraric acid, which exhibited the best binding capacity from the molecular docking study and 
concomitantly promising antioxidant capacity, also revealed reasonable pharmacokinetics and pharmacodynamics, with a significantly safe profile.

\section{Conclusions}

A comparative study on the qualitative and quantitative analysis of the polyphenolics in aqueous methanol extracts of the leaves, stems, flowers, and roots of E. spinosus is described herein for the first time. Echinops extracts constitute rich sources of polyphenols and thus could be used as powerful natural antioxidants, particularly the root extracts. The methanol extract of the roots demonstrated the highest reducing activity, whereas less activity was observed for the methanol extract of the stems. These results highlight the good correlation between the antioxidant activity and the phenolic content, with the highest value observed for the root extract. Additionally, molecular docking revealed that most of the tested compounds showed inhibition to both enzymes with varying degrees; however, tricaffeoyl-altraric acid, followed by dicaffeoyl-altraric acid, exhibited the best fit within the active site of NADPH oxidase (NO) and myeloperoxidase (MP). The results of molecular docking further ascertain the obtained in vitro results, with both tricaffeoyl-altraric acid and dicaffeoyl-altraric acid existing in the highest concentrations in the roots compared to other organs, and showed the highest antioxidant capacity, as revealed in all the performed assays. From the ADME/TOPAKT analyses, it can be concluded that most of the compounds revealed acceptable toxicity properties. However, the pharmacokinetics and pharmacodynamics require some treatment to be suitable for incorporation into pharmaceutical dosage forms. It is worth highlighting that tricaffeoylaltraric acid and dicaffeoyl-altraric acid, which exhibited the best binding capacity from the molecular docking study and concomitantly promising antioxidant capacity, also revealed reasonable pharmacokinetics and pharmacodynamics, with a significantly safe profile. However, assessment of the antioxidant and toxicity profile of Echinops extracts in vivo is an important next step so that their safety limits as a dietary antioxidant source for human health can be established, recognizing that the roots are already used as a spice in Morocco and Cameroon.

Author Contributions: Concept-A.B., P.M., and C.I.G.T.; design-A.B., P.M., C.I.G.T., F.S.Y. and M.L.A.; supervision-A.B. and C.I.G.T.; materials-A.B., P.M., S.P. and C.I.G.T.; data collection and/or processing-A.B., P.M., K.A.G., S.P., C.I.G.T., F.S.Y. and M.L.A.; analysis and/or interpretation-A.B., P.M., K.A.G., S.P., C.I.G.T., F.S.Y. and M.L.A.; literature search-A.B., P.M. and C.I.G.T.; writing-A.B., P.M., C.I.G.T., G.A.C. and F.S.Y.; critical reviews-A.B., P.M., C.I.G.T., G.A.C., N.M.A.M. and M.L.A.; funding-N.M.A.M. and M.L.A. All authors have read and agreed to the published version of the manuscript.

Funding: This work was partially funded by King Saud University Researchers Supporting Project number (RSP-2021/294), King Saud University, Riyadh, Saudi Arabia.

Institutional Review Board Statement: Not applicable.

Informed Consent Statement: Not applicable.

Data Availability Statement: Data are available in the manuscript.

Acknowledgments: This work was partially funded by King Saud University Researchers Supporting Project number (RSP-2021/294), King Saud University, Riyadh, Saudi Arabia.

Conflicts of Interest: One of the authors (G.A.C.) is from Natural Products Inc., Evanston, IL 60202, USA, the company had no role in the design of the study; in the collection, analyses, or interpretation of data; in the writing of the manuscript, or in the decision to publish the results.

\section{References}

1. Fathy, S.; Emam, M.; Agwa, S.A.; Zahra, F.A.; Youssef, F.; Sami, R. The antiproliferative effect of Origanum majorana on human hepatocarcinoma cell line: Suppression of NF-kB. Cell. Mol. Biol. 2016, 62, 80-84. [PubMed]

2. Yoshikawa, T.; Naito, Y. What is oxidative stress? Japan Med. Assoc. J. 2002, 45, 271-276.

3. Finaud, J.; Lac, G.; Filaire, E. Oxidative stress. Sports Med. 2006, 36, 327-358. [CrossRef] [PubMed] 
4. Rice-Evans, C.A.; Miller, N.J.; Bolwell, P.G.; Bramley, P.M.; Pridham, J.B. The relative antioxidant activities of plant-derived polyphenolic flavonoids. Free Rad. Res. 1995, 22, 375-383. [CrossRef]

5. Bitew, H.; Hymete, A. The genus Echinops: Phytochemistry and biological activities: A review. Front. Pharmacol. 2019, 10, 1234 [CrossRef]

6. Bouzabata, A.; Mahomoodally, F.; Tuberoso, C. Ethnopharmacognosy of Echinops spinosus L. in North Africa: A mini review. J. Comp. Med. Res. 2018, 8, 40-52. [CrossRef]

7. Talhouk, R.; Karam, C.; Fostok, S.; El-Jouni, W.; Barbour, E. Anti-inflammatory bioactivities in plant extracts. J. Med. Food. 2007, 10, 1-10. [CrossRef]

8. Abu-Rabia, A. Palestinian plant medicines for treating renal disorders: An inventory and brief history. Alt. Comp. Ther. 2005, 11, 295-300. [CrossRef]

9. Bouzabata, A.; Mahomoodally, M.F.; Cordell, G.A. Microscopic identification of Echinops spinosus ssp. bovei (Boiss.) Murb. using multivariate tests. J. Res. Pharm. 2019, 23, 797-803.

10. Eddouks, M.; Ouahidi, M.; Farid, O.; Moufid, A.; Khalidi, A.; Lemhadri, A. The use of medicinal plants in the treatment of diabetes in Morocco. Phytotherapy 2007, 5, 194-203. [CrossRef]

11. Chermat, S.; Gharzouli, R. Ethnobotanical study of medicinal flora in the North East of Algeria-An empirical knowledge in Djebel Zdimm (Setif). J. Mater. Sci. Eng. 2015, 5, 50-59.

12. Pavela, R.; Maggi, F.; Mbuntcha, H.; Woguem, V.; Fogang, H.P.D.; Womeni, H.M.; Tapondjou, L.A.; Barboni, L.; Nicoletti, M.; Canale, A. Traditional herbal remedies and dietary spices from Cameroon as novel sources of larvicides against filariasis mosquitoes? Parasitol. Res. 2016, 115, 4617-4626. [CrossRef] [PubMed]

13. Tbattou, M.; Belahyan, A.; Belahsen, R. Wild edible plants traditionally used in the countryside of El-Jadida coastal area in the center of Morocco. Life Sci. Leaflets. 2016, 75, 28-48.

14. Agyare, C.; Obiri, D.D.; Boakye, Y.D.; Osafo, N. Anti-inflammatory and analgesic activities of African medicinal plants. Med.Plant Res. Afr. 2013, 725-752.

15. Bouattour, E.; Fakhfakh, J.; Affes, M.; Chawech, R.; Damak, M.; Jarraya, R. Chemical constituents of Echinops spinosus from Tunisia Chem. Nat.Com. 2017, 53, 984-987. [CrossRef]

16. Dobignard, A.; Chatelain, C. Volume 2: Dicotyledoneae: Acanthaceae-Asteraceae. In Index of the Flora of North Africa; The Conservatory and Botanical Garden of the City of Geneva: Genève, Switzerland, 2011.

17. Deiana, M.; Montoro, P.; Jerković, I.; Atzeri, A.; Marijanović, Z.; Serreli, G.; Piacente, S.; Tuberoso, C.I.G. First characterization of Pompia intrea candied fruit: The headspace chemical profile, polar extract composition and its biological activities. Food Res. Int. 2019, 120, 620-630. [CrossRef]

18. Altyar, A.E.; Ashour, M.L.; Youssef, F.S. Premna odorata: Seasonal metabolic variation in the essential oil composition of its leaf and verification of its anti-ageing potential via in vitro assays and molecular modelling. Biomolecules 2020, 10, 879. [CrossRef]

19. Youssef, F.S.; Mamatkhanova, M.A.; Mamadalieva, N.Z.; Zengin, G.; Aripova, S.F.; Alshammari, E.; Ashour, M.L. Chemical profiling and discrimination of essential oils from six Ferula species using GC analyses coupled with chemometrics and evaluation of their antioxidant and enzyme inhibitory potential. Antibiotics 2020, 9, 518. [CrossRef]

20. Alam, M.S.; Singh, A. Sorption isotherm characteristics of aonla flakes. J. Food Sci. Technol. 2011, 48, 335-343. [CrossRef]

21. Pękal, A.; Pyrzynska, K. Evaluation of aluminium complexation reaction for flavonoid content assay. Food Anal. Meth. 2014, 7, 1776-1782. [CrossRef]

22. Janibekov, A.A.; Youssef, F.S.; Ashour, M.L.; Mamadalieva, N.Z. New flavonoid glycosides from two Astragalus species (Fabaceae) and validation of their antihyperglycaemic activity using molecular modelling and in vitro studies. Ind. Crops Prod. 2018, 118, 142-148. [CrossRef]

23. Ashour, M.L.; Youssef, F.S.; Gad, H.A.; El-Readi, M.Z.; Bouzabata, A.; Abuzeid, R.M.; Sobeh, M.; Wink, M. Evidence for the anti-inflammatory activity of Bupleurum marginatum (Apiaceae) extracts using in vitro and in vivo experiments supported by virtual screening. J. Pharm. Pharmacol. 2018, 70, 952-963. [CrossRef] [PubMed]

24. Youssef, F.S.; Ovidi, E.; Musayeib, N.M.A.; Ashour, M.L. Morphology, anatomy and secondary metabolites investigations of Premna odorata Blanco and evaluation of its anti-tuberculosis activity using in vitro and in silico studies. Plants 2021, 10, 1953. [CrossRef]

25. Mamadalieva, N.Z.; Youssef, F.S.; Hussain, H.; Zengin, G.; Mollica, A.; Al Musayeib, N.M.; Ashour, M.L.; Westermann, B.; Wessjohann, L.A. Validation of the antioxidant and enzyme inhibitory potential of selected triterpenes using in vitro and in silico studies, and the evaluation of their ADMET properties. Molecules 2021, 26, 6331. [CrossRef]

26. Abiven, S.; Recous, S.; Reyes, V.; Oliver, R. Mineralisation of $\mathrm{C}$ and $\mathrm{N}$ from root, stem and leaf residues in soil and role of their biochemical quality. Biol. Fert. Soils. 2005, 42, 119-128. [CrossRef]

27. Horai, H.; Arita, M.; Kanaya, S.; Nihei, Y.; Ikeda, T.; Suwa, K.; Ojima, Y.; Tanaka, K.; Tanaka, S.; Aoshima, K. MassBank: A public repository for sharing mass spectral data for life sciences. J. Mass Spect. 2010, 45, 703-714. [CrossRef]

28. D'Urso, G.; Montoro, P.; Piacente, S. Detection and comparison of phenolic compounds in different extracts of black currant leaves by liquid chromatography coupled with high-resolution ESI-LTQ-Orbitrap MS and high-sensitivity ESI-Qtrap MS. J. Pharm. Biomed. Anal. 2020, 179, 112926. [CrossRef]

29. Boumaraf, M.; Benyahia, S.; Mekkiou, R.; Benayache, S.; Benayache, F. Flavonoids from ethyl acetate extract of Echinops spinosus (Asteraceae). Der Pharma Chemica 2016, 8, 158-160. 
30. Tsafantakis, N.; Zelianeos, K.; Termentzi, A.; Vontzalidou, A.; Aligiannis, N.; Fokialakis, N. Triterpenes from Echinops spinosissimus Turra subsp. spinosissimus. Phytochem. Lett. 2019, 30, 273-277. [CrossRef]

31. Bouattour, E.; Fakhfakh, J.; Frikha Dammak, D.; Jabou, K.; Damak, M.; Mezghani Jarraya, R. Hexane extract of Echinops spinosissimus Turra subsp. spinosus from tunisia: A potential source of acetylated sterols-investigation of its biological activities. Chem. Biodivers. 2016, 13, 1674-1684. [CrossRef]

32. Burlec, A.F.; Pecio, Ł.; Mircea, C.; Cioancă, O.; Corciovă, A.; Nicolescu, A.; Oleszek, W.; Hăncianu, M. Chemical profile and antioxidant activity of Zinnia elegans Jacq. fractions. Molecules 2019, 24, 2934. [CrossRef] [PubMed]

33. El-Moaty, H.I.A. Antimicrobial activity of Taverniera lappacea Forssk extract affected by its active constituents. Indo Am. J. Pharm. Sci. 2016, 3, 1092-1095.

34. Jaiswal, R.; Kiprotich, J.; Kuhnert, N. Determination of the hydroxycinnamate profile of 12 members of the Asteraceae family. Phytochemistry 2011, 72, 781-790. [CrossRef]

35. Liu, Y.; Ye, M.; Guo, H.-Z.; Zhao, Y.-Y.; Guo, D.-A. New thiophenes from Echinops grijisii. J. Asian Nat. Prod. Res. 2002, 4, 175-178. [CrossRef]

36. Dong, L.; Ning, L.; Wan, X.; Peng, Z.; Zhong-jun, M.; Xian, L. Chemical constituents of the root of Echinops grijisii Hance. Shenyang Yao Ke Da Xue Xue Bao 2008, 8, 007.

37. Abbet, C.; Slacanin, I.; Corradi, E.; De Mieri, M.; Hamburger, M.; Potterat, O. Comprehensive analysis of Cirsium spinosissimum Scop., a wild alpine food plant. Food Chem. 2014, 160, 165-170. [CrossRef]

38. Ruan, J.; Li, Z.; Yan, J.; Huang, P.; Yu, H.; Han, L.; Zhang, Y.; Wang, T. Bioactive constituents from the aerial parts of Pluchea indica less. Molecules 2018, 23, 2104. [CrossRef]

39. Takenaka, M.; Yan, X.; Ono, H.; Yoshida, M.; Nagata, T.; Nakanishi, T. Caffeic acid derivatives in the roots of yacon (Smallanthus sonchifolius). J. Agri. Food Chem. 2003, 51, 793-796. [CrossRef]

40. Vega, R.J.S.; Xolalpa, N.C.; Castro, A.J.A.; Pérez González, C.; Pérez Ramos, J.; Pérez Gutiérrez, S. Terpenes from natural products with potential anti-inflammatory activity. In Terpenes and Terpenoids; Intech Open: London, UK, 2018; pp. 59-85.

41. Semwal, R.B.; Semwal, D.K.; Combrinck, S.; Viljoen, A. Butein: From ancient traditional remedy to modern nutraceutical Phytochem. Lett. 2015, 11, 188-201. [CrossRef]

42. Karar, M.E.; Kuhnert, N. UPLC-ESI-Q-TOF-MS/MS characterization of phenolics from Crataegus monogyna and Crataegus laevigata (Hawthorn) leaves, fruits and their herbal derived drops (Crataegutt Tropfen). J. Chem. Biol. Ther. 2015, 1, $2572-0406$.

43. Zheng, Y.-Y.; Shen, N.-X.; Liang, Z.-Y.; Shen, L.; Chen, M.; Wang, C.-Y. Paraherquamide J, a new prenylated indole alkaloid from the marine-derived fungus Penicillium janthinellum HK1-6. Nat. Prod. Res. 2020, 34, 378-384. [CrossRef] [PubMed]

44. Ashour, M.A.-G. New diacyl flavonoid derivatives from the Egyptian plant Blepharis edulis (Forssk.) Pers. Bull. Fac. Pharm. Cairo Uni. 2015, 53, 11-17. [CrossRef]

45. Clifford, M.N.; Jaganath, I.B.; Ludwig, I.A.; Crozier, A. Chlorogenic acids and the acyl-quinic acids: Discovery, biosynthesis, bioavailability and bioactivity. Nat. Prod. Rep. 2017, 34, 1391-1421. [CrossRef]

46. El-Seedi, H.R.; El-Said, A.M.; Khalifa, S.A.; Goransson, U.; Bohlin, L.; Borg-Karlson, A.-K.; Verpoorte, R. Biosynthesis, natural sources, dietary intake, pharmacokinetic properties, and biological activities of hydroxycinnamic acids. J. Agri. Food Chem. 2012, 60, 10877-10895. [CrossRef]

47. Khedher, O.; Moussaoui, Y.; Salem, R.B. Solvent effects on phenolic contents and antioxidant activities of the Echinops spinosus and the Limoniastrum monopetalum. Res. J. Pharm. Biol. Chem. Sci. 2014, 5, 66-76.

48. Gheffour, K.; Boucherit, K.; Boucherit-Otmani, Z. Phytochemical study and evaluation of the antioxidant activity of Echinops spinosus extracts. Phytotherapy 2015, 13, 288-294. [CrossRef]

49. Samir, H.; Abbas, M.S.; Soliman, A.S.; Lotfy, R.A. Phytochemical screening, antioxidant and cytotoxic activities of some plants species derived from the northwestern coast of Egypt. Res. J. Pharm. Biol. Chem. Sci. 2018, 9, 894. 